\title{
STEM imaging of irradiation induced defects in Eurofer97 steel variants irradiated in the EUROfusion collaboration
}

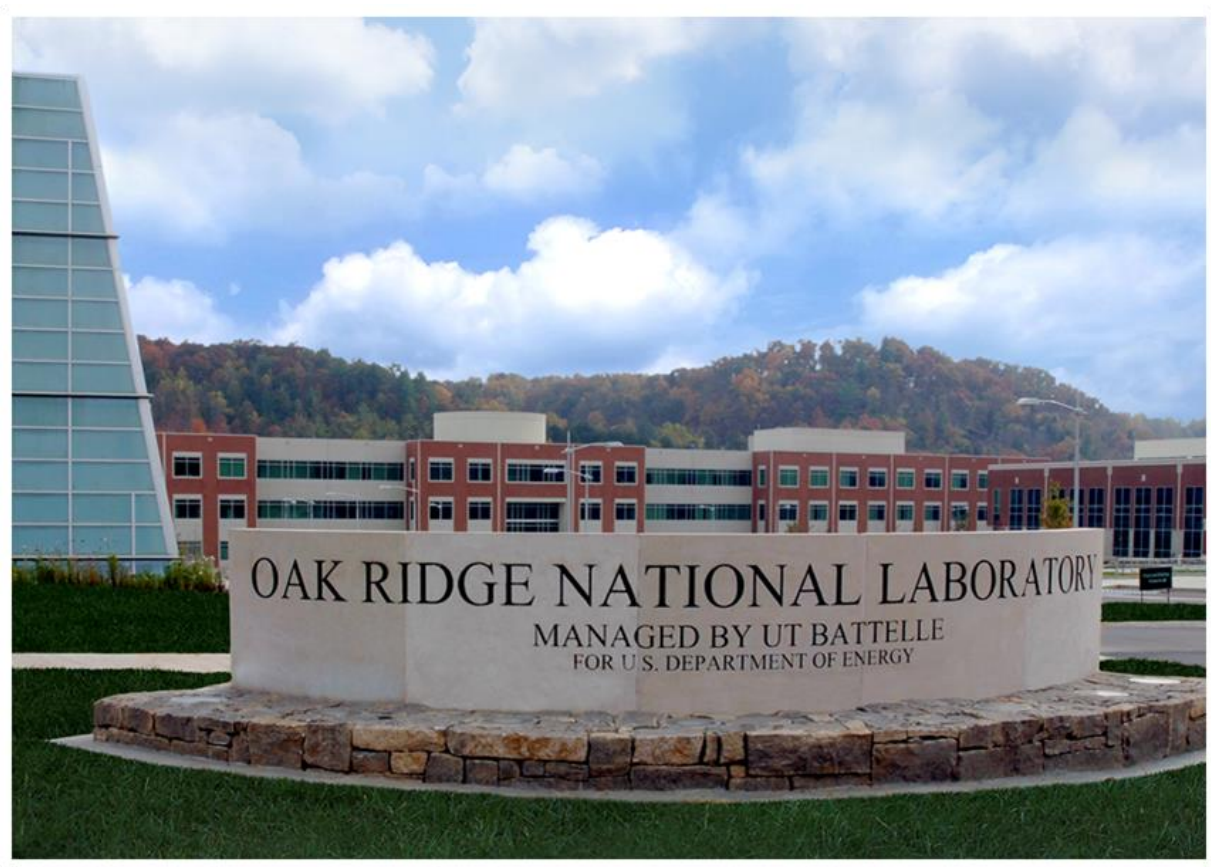

A. Bhattacharya

T. Graening

J.W. Geringer

Y. Katoh

January 12, 2022 


\section{DOCUMENT AVAILABILITY}

Reports produced after January 1, 1996, are generally available free via US Department of Energy (DOE) SciTech Connect.

Website http://www.osti.gov/scitech/

Reports produced before January 1, 1996, may be purchased by members of the public from the following source:

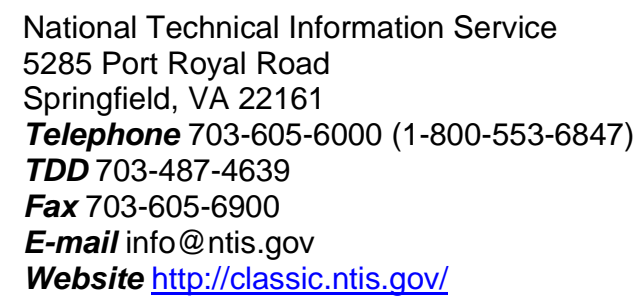

Reports are available to DOE employees, DOE contractors, Energy Technology Data Exchange representatives, and International Nuclear Information System representatives from the following source:

Office of Scientific and Technical Information

PO Box 62

Oak Ridge, TN 37831

Telephone 865-576-8401

Fax 865-576-5728

E-mail reports@osti.gov

Website http://www.osti.gov/contact.html

This report was prepared as an account of work sponsored by an agency of the United States Government. Neither the United States Government nor any agency thereof, nor any of their employees, makes any warranty, express or implied, or assumes any legal liability or responsibility for the accuracy, completeness, or usefulness of any information, apparatus, product, or process disclosed, or represents that its use would not infringe privately owned rights. Reference herein to any specific commercial product, process, or service by trade name, trademark, manufacturer, or otherwise, does not necessarily constitute or imply its endorsement, recommendation, or favoring by the United States Government or any agency thereof. The views and opinions of authors expressed herein do not necessarily state or reflect those of the United States Government or any agency thereof. 
Materials Science and Technology Division

STEM imaging of irradiation induced defects in Eurofer97 steel variants irradiated in the EUROfusion collaboration

\author{
Arunodaya Bhattacharya \\ Tim Graening \\ Josina W. Geringer \\ Yutai Katoh
}

January 2022

\author{
Prepared by \\ OAK RIDGE NATIONAL LABORATORY \\ Oak Ridge, TN 37831-6283 \\ managed by \\ UT-BATTELLE, LLC \\ for the \\ Karlsruhe Institute of Technology \\ under contract NFE-16-06240
}




\section{CONTENTS}

CONTENTS

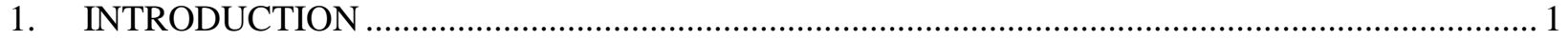

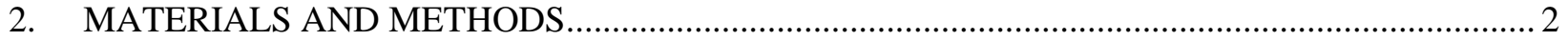

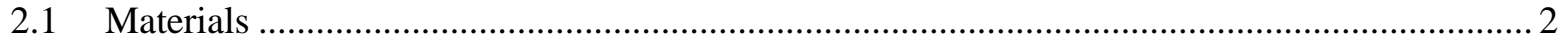

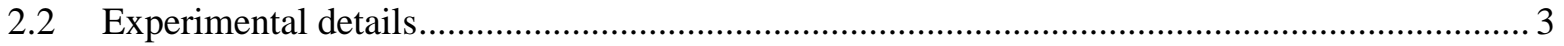

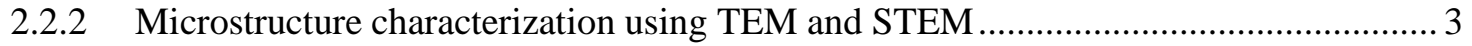

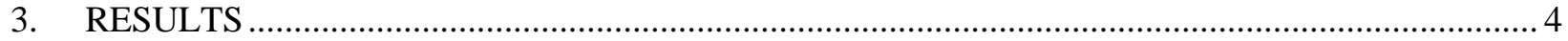

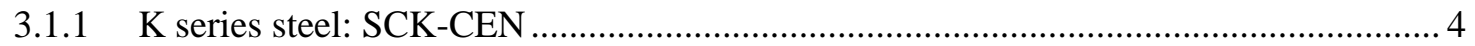

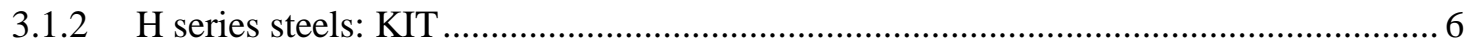

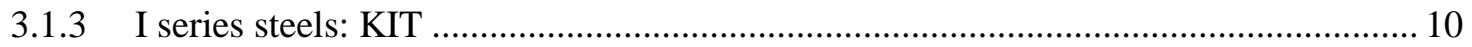

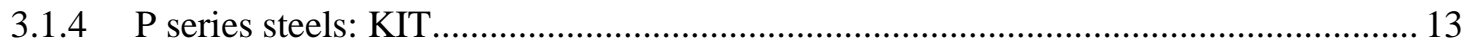

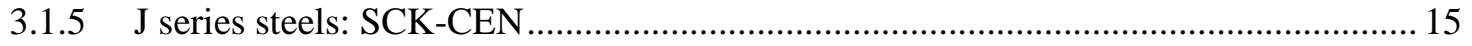

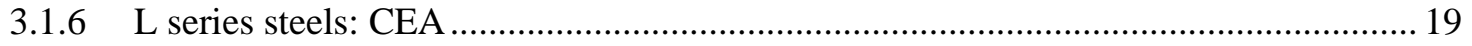

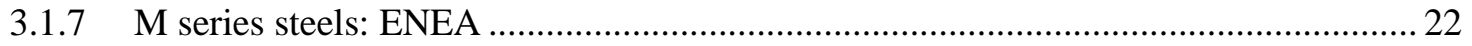

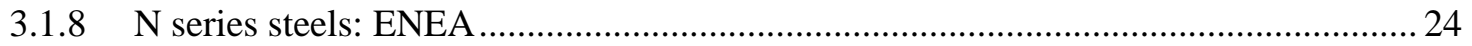

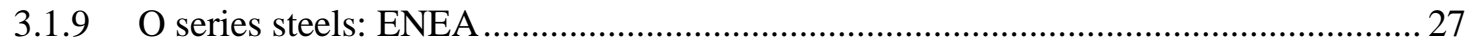

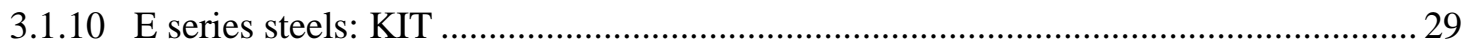

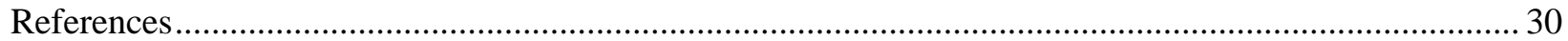




\section{INTRODUCTION}

Ten exploratory variants of Eurofer97 reduced activation ferritic martensitic (RAFM) steel were irradiated in HFIR to $\sim 2.94-32.4 \mathrm{dpa}, 300 \pm 30{ }^{\circ} \mathrm{C}$ as a part of the EUROfusion collaboration. The irradiations were performed in rabbit capsules. ES21-22 capsule were used for irradiating SS-J3 tensile samples while M4CVN bend bar samples were irradiated in ES31-35 capsules. The mechanical properties and multi-length scale characterization of the microstructures of these ten steels, designated as $\mathrm{H}, \mathrm{I}, \mathrm{P}, \mathrm{J}, \mathrm{K}$, $\mathrm{L}, \mathrm{M}, \mathrm{N}, \mathrm{O}, \mathrm{P}$ and reference $\mathrm{E}$, in the nonirradiated form was reported in Ref. [1] while their irradiated properties and some microstructure analysis was reported in Ref. [2]. Here, additional microstructures using TEM/STEM and STEM-EDX of the irradiated steels is presented. Characterization was performed at the Low Activation Materials Development and Analysis (LAMDA) laboratory. 


\section{MATERIALS AND METHODS}

\subsection{Materials}

The different steels that were provided by KIT for the irradiation campaign are summarized in Table 1. These specimens were in the shape of sub-sized tensiles (SS-J3), 4-notch fracture toughness bend bar specimens (M4CVN) and MPC1 multipurpose coupons.

Table 1 and Table 2 also summarizes the heat treatment and chemical composition information that was provided to ORNL.

Table 1. Summary of different Eurofer-97 steel variants. AQ: air quenched, WQ: water quenched, LT: low temperature application, HT: high temperature application.

\begin{tabular}{|c|c|c|c|c|}
\hline M-Code & Material type & Heat & Condition & Provider \\
\hline $\mathrm{E}$ & EUROFER97/2 & 993391 & $980^{\circ} \mathrm{C} / 0.5 \mathrm{~h}+\mathrm{AQ}+760^{\circ} \mathrm{C}+\mathrm{AC}($ new reference $)$ & KIT \\
\hline $\mathrm{H}$ & EUROFER-LT & J362A & $1000^{\circ} \mathrm{C} / 0.5 \mathrm{~h}+\mathrm{WQ}+820^{\circ} \mathrm{C}+\mathrm{AC}$ & KIT \\
\hline I & EUROFER-LT & J363A & $1000^{\circ} \mathrm{C} / 0.5 \mathrm{~h}+\mathrm{WQ}+820^{\circ} \mathrm{C}+\mathrm{AC}$ & KIT \\
\hline $\mathrm{P}$ & EUROFER-LT & J361A & $1000^{\circ} \mathrm{C} / 0.5 \mathrm{~h}+\mathrm{WQ}+820^{\circ} \mathrm{C}+\mathrm{AC}$ & KIT \\
\hline $\bar{L}$ & EUROFER97/2 & 994578 & $1150^{\circ} \mathrm{C} / 0.5 \mathrm{~h}+\mathrm{AQ}+700^{\circ} \mathrm{C}+\mathrm{AC}$ & CEA \\
\hline \multirow[t]{2}{*}{$\mathrm{J}$} & \multirow[t]{2}{*}{ EUROFER-LT } & \multirow[t]{2}{*}{ I196C } & $\begin{array}{l}\text { TMT: } 1250^{\circ} \mathrm{C} / 1 \mathrm{~h} \text { and then rolling to a final rolling } \\
\text { temperature of } 850^{\circ} \mathrm{C} \text { in } 6 \text { rolling steps with a } \\
\text { reduction of } 20-30 \% \text { for each rolling pass, then AC. }\end{array}$ & \multirow[t]{2}{*}{ SCK.CEN } \\
\hline & & & $\mathrm{Q} \& \mathrm{~T}: 880^{\circ} \mathrm{C} / 0.5 \mathrm{~h}+\mathrm{WQ}+750^{\circ} \mathrm{C} / 2 \mathrm{~h}+\mathrm{AC}$ & \\
\hline \multirow[t]{2}{*}{ K } & \multirow[t]{2}{*}{ EUROFER-HT } & \multirow[t]{2}{*}{ I $427 \mathrm{~A}$} & $\begin{array}{l}\text { TMT: } 1250^{\circ} \mathrm{C} / 1 \mathrm{~h} \text { and then rolling to a final rolling } \\
\text { temperature of } 850^{\circ} \mathrm{C} \text { in } 6 \text { rolling steps with a } \\
\text { reduction of } 20-30 \% \text { for each rolling pass, then AC. }\end{array}$ & \multirow[t]{2}{*}{ SCK.CEN } \\
\hline & & & Q\&T: $1050^{\circ} \mathrm{C} / 15 \mathrm{~min}+\mathrm{WQ}+675^{\circ} \mathrm{C} / 1.5 \mathrm{~h}+\mathrm{AC}$ & \\
\hline M & EUROFER97/2 & 993391 & $\begin{array}{l}1020^{\circ} \mathrm{C} / 0.5 \mathrm{~h}+\mathrm{AQ}+1020^{\circ} \mathrm{C} / 0.5 \mathrm{~h}+\mathrm{AQ}+760^{\circ} \mathrm{C} / 1.5 \mathrm{~h} \\
+\mathrm{AC} \text { (double austenitization) }\end{array}$ & ENEA \\
\hline \multirow[t]{2}{*}{$\mathrm{O}$} & \multirow[t]{2}{*}{ EUROFER-LT } & \multirow[t]{2}{*}{ VM2991 } & $\begin{array}{l}\text { TMT: } 1080^{\circ} \mathrm{C} / 1 \mathrm{~h} \text {, cooling to } 650^{\circ} \mathrm{C} \text { and rolling, } \\
\text { reduction } 40 \% \text { (from } 30 \mathrm{~mm} \text { to } 18 \mathrm{~mm} \text { ) }\end{array}$ & \multirow[t]{2}{*}{ ENEA } \\
\hline & & & Tempering: $760^{\circ} \mathrm{C} / 1 \mathrm{~h}+\mathrm{AC}$ & \\
\hline $\mathrm{N}$ & EUROFER-LT & VM2897 & $\begin{array}{l}920^{\circ} \mathrm{C} / 1.5 \mathrm{~h}+\mathrm{AQ}+920^{\circ} \mathrm{C} / 1.5 \mathrm{~h}+\mathrm{AQ}+760^{\circ} \mathrm{C} / 1 \mathrm{~h}+ \\
\mathrm{AC} \text { (double austenitization) }\end{array}$ & ENEA \\
\hline
\end{tabular}


Table 2. Chemical compositions of different Eurofer-97 steel variants provided by KIT. All values are in wt.\%.

\begin{tabular}{|l|l|l|l|l|l|l|l|l|l|}
\hline Element & $\mathbf{P}$ & $\mathbf{H}$ & $\mathbf{I}$ & $\mathbf{E}, \mathbf{M}$ & $\mathbf{L}$ & $\mathbf{J}$ & $\mathbf{K}$ & $\mathbf{O}$ & $\mathbf{N}$ \\
\hline $\mathrm{Cr}$ & 8.7 & 8.7 & 8.73 & 8.83 & 9.14 & 9 & 7.84 & 8.8 & 9.04 \\
\hline $\mathrm{C}$ & 0.105 & 0.0583 & 0.11 & 0.107 & 0.106 & 0.107 & 0.017 & 0.06 & 0.092 \\
\hline $\mathrm{Mn}$ & 0.021 & 0.0223 & 0.0189 & 0.527 & 0.54 & 0.39 & $<0.03$ & 0.5 & 0.11 \\
\hline $\mathrm{V}$ & 0.2 & 0.353 & 0.351 & 0.2 & 0.2 & 0.22 & 0.2212 & 0.3 & $<0.05$ \\
\hline $\mathrm{N}$ & 0.0445 & 0.0465 & 0.0422 & 0.019 & 0.038 & 0.022 & 0.022 & 0.07 & 0.0024 \\
\hline $\mathrm{W}$ & 1.14 & 1.07 & 1.08 & 1.081 & 1.11 & 1.1 & 0.99 & 0.97 & 0.99 \\
\hline $\mathrm{Ta}$ & 0.093 & 0.1 & 0.0918 & 0.117 & 0.12 & 0.11 & 0.1265 & 0.05 & 0.092 \\
\hline $\mathrm{Si}$ & 0.032 & 0.0362 & 0.0363 & 0.0352 & 0.025 & $<0.04$ & $<0.04$ & 0.15 & 0.037 \\
\hline $\mathrm{S}$ & 0.0015 & 0.0014 & 0.0011 & 0.0009 & 0.0037 & 0.0011 & 0.0011 & 0.003 & 0.001 \\
\hline $\mathrm{B}$ & $<0.0005$ & $<0.0005$ & $<0.0005$ & $<0.0005$ & 0.0011 & $<0.0005$ & $<0.0005$ & $<0.001$ & $<0.001$ \\
\hline $\mathrm{Ti}$ & $<0.0001$ & $<0.0001$ & $<0.0001$ & $<0.0001$ & 0.001 & $<0.0001$ & $<0.0001$ & $<0.01$ & $<0.01$ \\
\hline $\mathrm{O}$ & 0.0036 & 0.0022 & 0.0052 & 0.0043 & $<0.001$ & 0.007 & 0.0043 & 0.006 & $<0.004$ \\
\hline $\mathrm{Nb}$ & $<0.0004$ & $<0.0004$ & $<0.0004$ & $<0.0004$ & 0.004 & $<0.0004$ & $<0.0004$ & $<0.01$ & $<0.01$ \\
\hline $\mathrm{Mo}$ & 0.0012 & 0.0009 & 0.0009 & 0.0009 & 0.002 & & & $<0.01$ & $<0.01$ \\
\hline $\mathrm{Ni}$ & 0.0057 & 0.004 & 0.0036 & 0.0034 & 0.01 & & & $<0.02$ & $<0.02$ \\
\hline $\mathrm{Cu}$ & 0.0075 & 0.0077 & 0.0072 & 0.007 & 0.003 & & & $<0.01$ & $<0.01$ \\
\hline $\mathrm{Al}$ & 0.0016 & 0.0017 & 0.0014 & 0.0012 & 0.002 & & & $<0.01$ & $<0.01$ \\
\hline $\mathrm{Co}$ & 0.0021 & 0.0017 & 0.0017 & 0.0017 & 0.003 & & & $<0.01$ & $<0.01$ \\
\hline $\begin{array}{l}\mathrm{As}, \mathrm{Zr}, \mathrm{Sn}, \\
\mathrm{Sb}\end{array}$ & & & & & $<0.007$ & & & $<0.005$ & $<0.005$ \\
\hline $\mathrm{P}$ & & & & & 0.0015 & & & $<0.006$ & $<0.005$ \\
\hline
\end{tabular}

\subsection{Experimental details}

\subsubsection{Microstructure characterization using TEM and STEM}

TEM/STEM characterization of the irradiated samples was performed on focused ion beam (FIB) lift out specimens. The FIB lift outs were prepared from the slivers cut from undeformed head sections of the SS-J3 tensile samples. For FIB preparation, a tungsten filament based FEI Quanta DualBeam FIB-SEM was used. Initial lift out was performed using $30 \mathrm{kV}$ gallium $(\mathrm{Ga})$ ions. While thinning, the energy and current of the Ga beam was reduced progressively to minimize milling induced damage to the thin foils. Final polishing was performed using $2 \mathrm{kV} \mathrm{Ga}$ ions for 10 minutes on each sample surface, followed by Argon nanomilling to energies upto $0.9 \mathrm{kV}$ to minimize FIB induced defects and artifacts. TEM/STEM imaging was performed using a XFEG based FEI F200X Talos STEM operating at $200 \mathrm{kV}$, equipped with high resolution STEM detectors and a FEI 4096×4096 resolution "Ceta" CCD camera. RAFM steels contain high dislocation densities. Therefore, imaging of precipitate phases in RAFM steels is tedious using conventional TEM/STEM because both dislocations and precipitates are imaged close to diffraction conditions (either two-beam or down-axis). Moreover, because of the similar atomic number $(\mathrm{Z})$ of the constituents of $\mathrm{M}_{23} \mathrm{C}_{6} / \mathrm{M}_{7} \mathrm{C}_{3}$ carbides and the steel matrix (Fe/Cr), these carbides do not render a very sharp contrast in TEM/STEM images. To overcome these issues, the precipitates were imaged using high-count rate EDX mapping of the samples using FEI F200X Talos STEM. This method also avoided the error prone 
task of differentiating between FIB milling induced defects and small precipitates. The EDX maps were recorded for 1 hour for each sample, where the average count rate varied between 55-72k counts per sec. For the sake of completeness, the nonirradiated results of the ten steels are also presented here, that are adapted from Ref. [1]. Here, one must note that characterizing the dislocation loop microstructure of RAFM steels is critical to understand the hardening/embrittlement behavior. But producing FIB milling induced defect free samples is a challenge even with Ar nanomill. This is particularly important for relatively low irradiation temperatures like $300{ }^{\circ} \mathrm{C}$ in the present study where it is well known that dislocation loops in RAFM steels would be small. Even though careful FIB preparation may largely minimize FIB defects, it is complex to fully eliminate this problem.

\section{RESULTS}

\subsubsection{K series steel: SCK-CEN}

In nonirradiated condition, $\mathrm{K}$ series steel consisted of no precipitates. This steel had comprised of large prior austenite grains. For convenience, the nonirradiated microstructure and the STEM-EDX mapping results that were reported in Ref. [1] are shown in Figure 1. After irradiation, no significant evolution of the precipitation distribution occurred. Medium angle annular dark field (MAADF) and associated EDX maps taken from the irradiated sample are shown in Figure 2. It is evident in these figures that despite a few visible precipitates, the microstructure did not show evidence of any chemical redistribution or secondary phase precipitation of any sort. STEM-BF (bright dield) mode and low angle annular dark field (LAADF) imaging was performed to characterize the irradiation-induced extended defects. This revealed that dislocation loops formed in the steel after the irradiation, as shown in Figure 3. Some of the identified loops are highlighted using arrows in the BF image. Figure 4 presents more examples of dislocation loops observed in this steel after irradiation and imaged at differing magnifications in STEMBF mode. It is evident that the dislocation loop microstructure after irradiation was quite complex: numerous individual loops were identified but many loops were seen interacting with dislocation lines and/or with the neighboring loops.
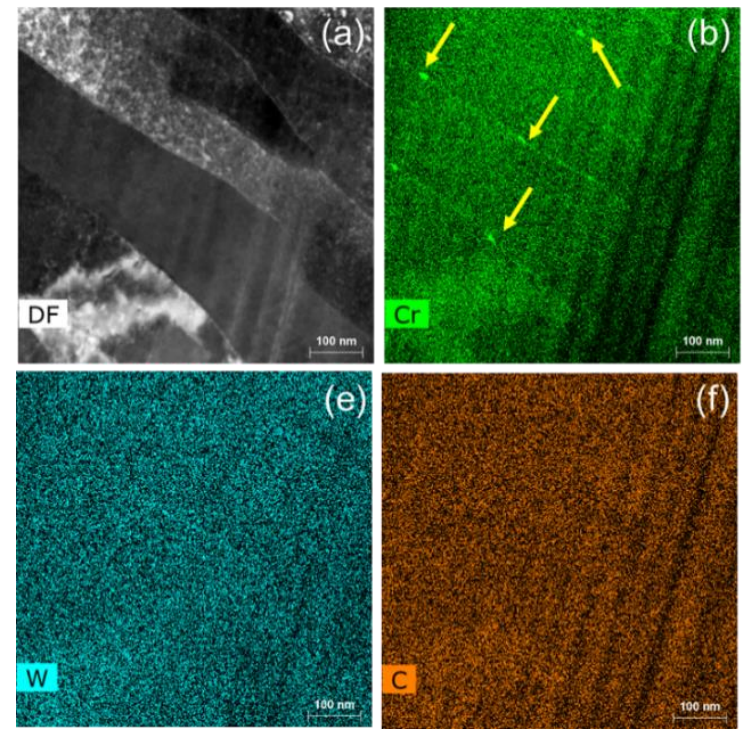
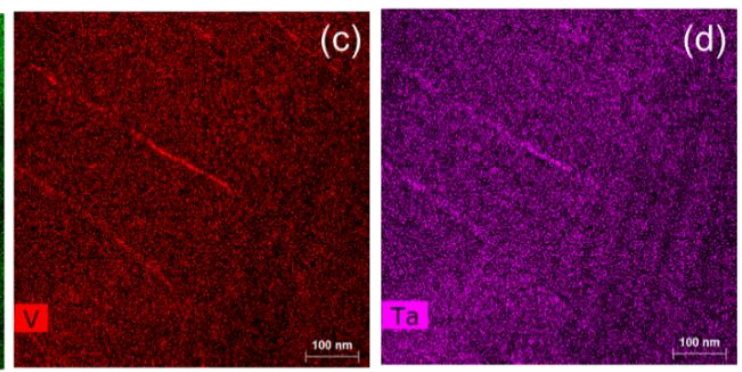

(g)
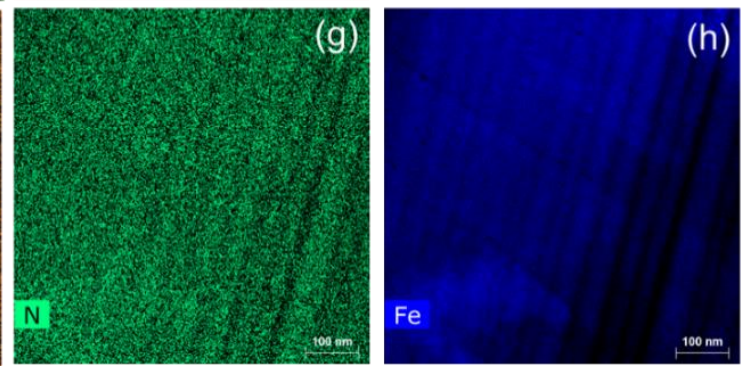

Figure 1: STEM-EDX mapping of K series steel in nonirradiated state. (a) MAADF image, (b-h) EDX maps of different elements in the steel. Dark lines at the left of EDX maps are artefacts due to FIB milling curtains. Yellow arrows show some $\mathrm{Cr}$ rich areas on the laths. 
Because of the complexity of performing g.b analysis on the relatively complex loop microstructure, their Burgers vector was not revealed. Numerous black dots were detected in all the STEM images when dislocation loops were imaged. Here, it is difficult to say whether these black dots were real features or created by FIB milling. These were not included for estimating the quantitative results. The average diameter and number density of the dislocation loops were $11 \mathrm{~nm}$ and $\sim 1.8 \times 10^{22} \mathrm{~m}^{-3}$.
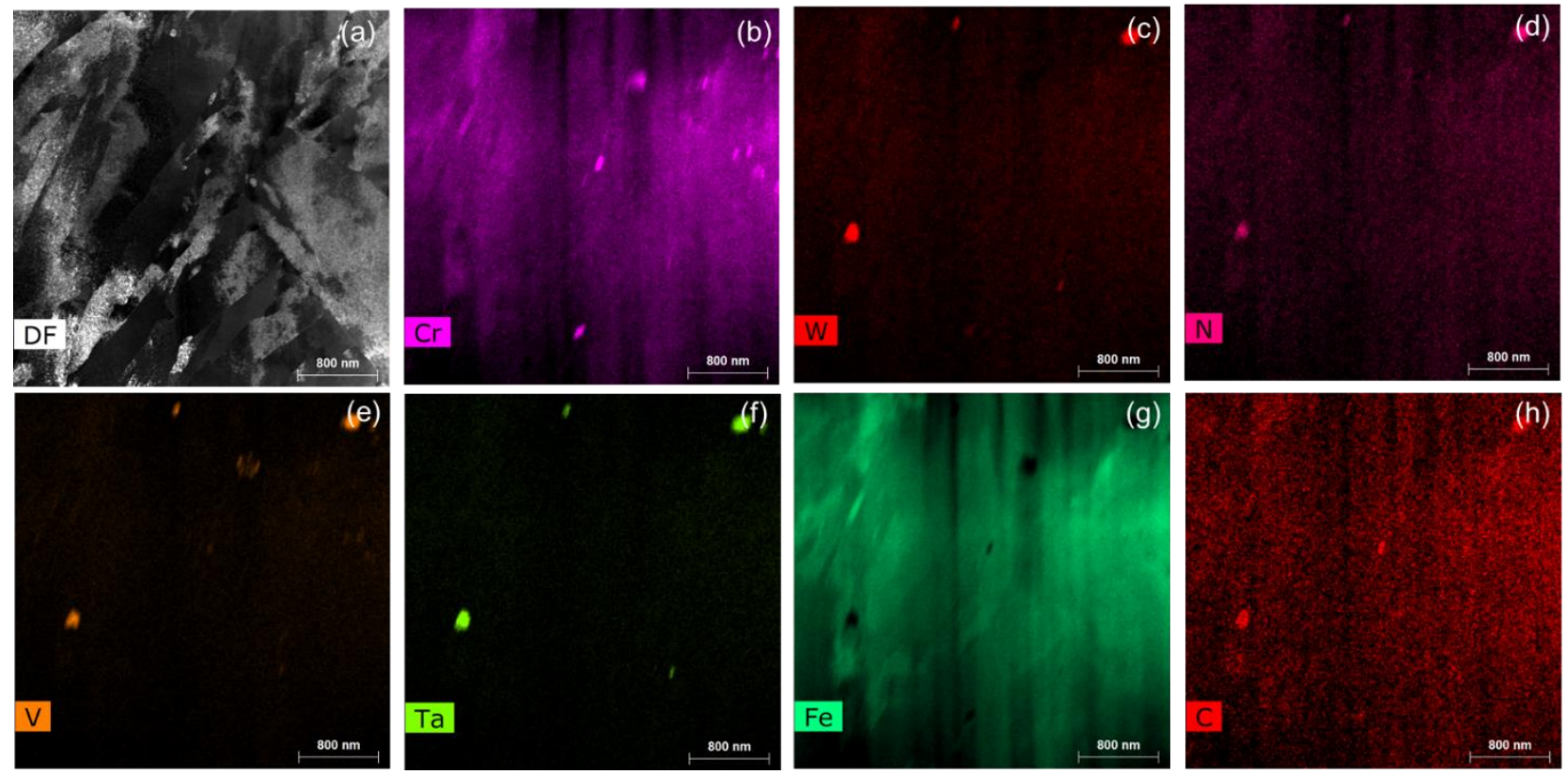

Figure 2: STEM-EDX mapping of K series steel after irradiation. (a) MAADF image, (b-h) EDX maps of different elements in the steel. Some small precipitates were seen, but the microstructure remained mostly under tempered.
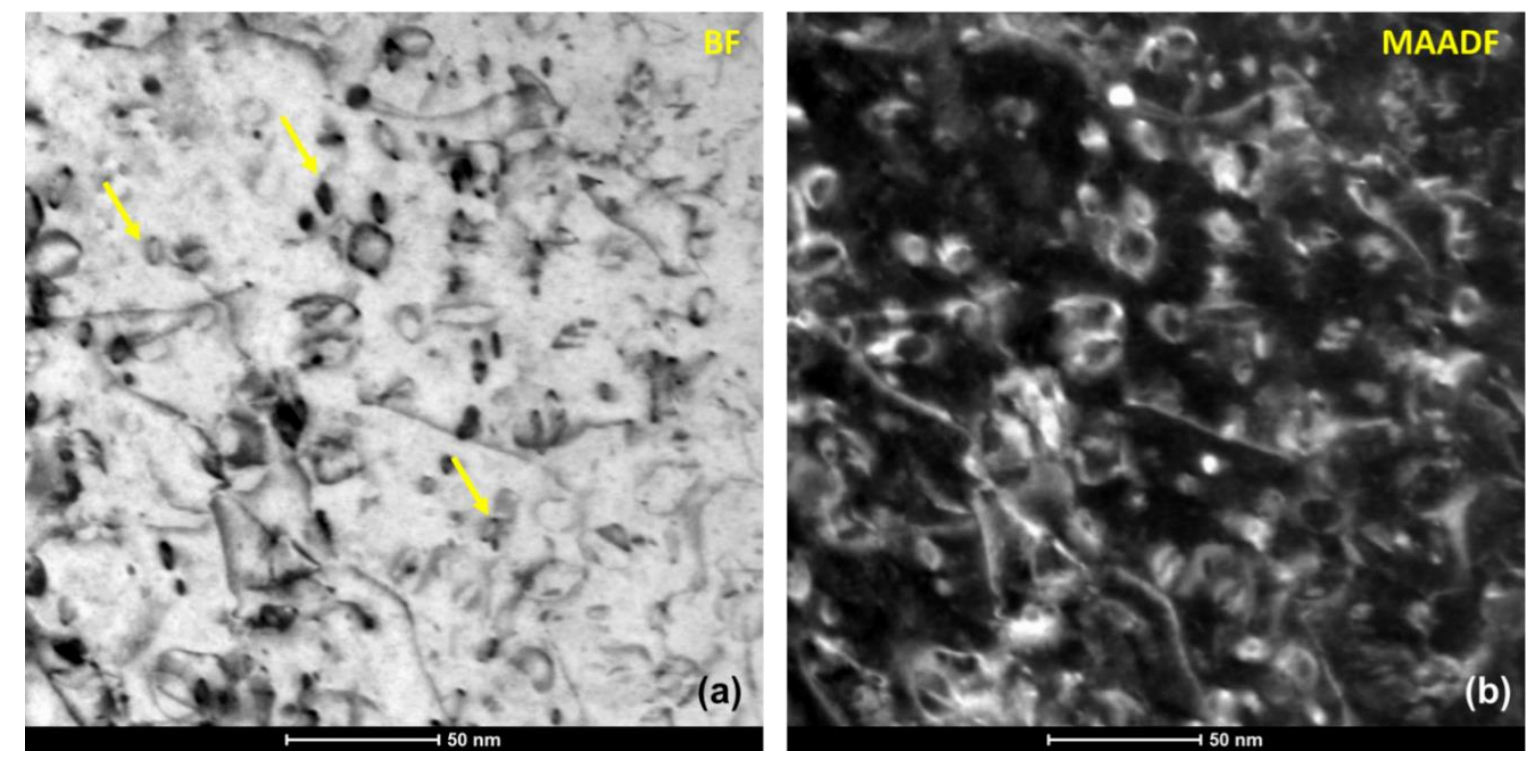

Figure 3: Dislocation loops in K series steel after irradiation. (a) STEM-BF. (b) MAADF. Imaging performed close to [001] zone axis using a $<110>$ type $g$ vector. Some loops are indicated using arrows. 

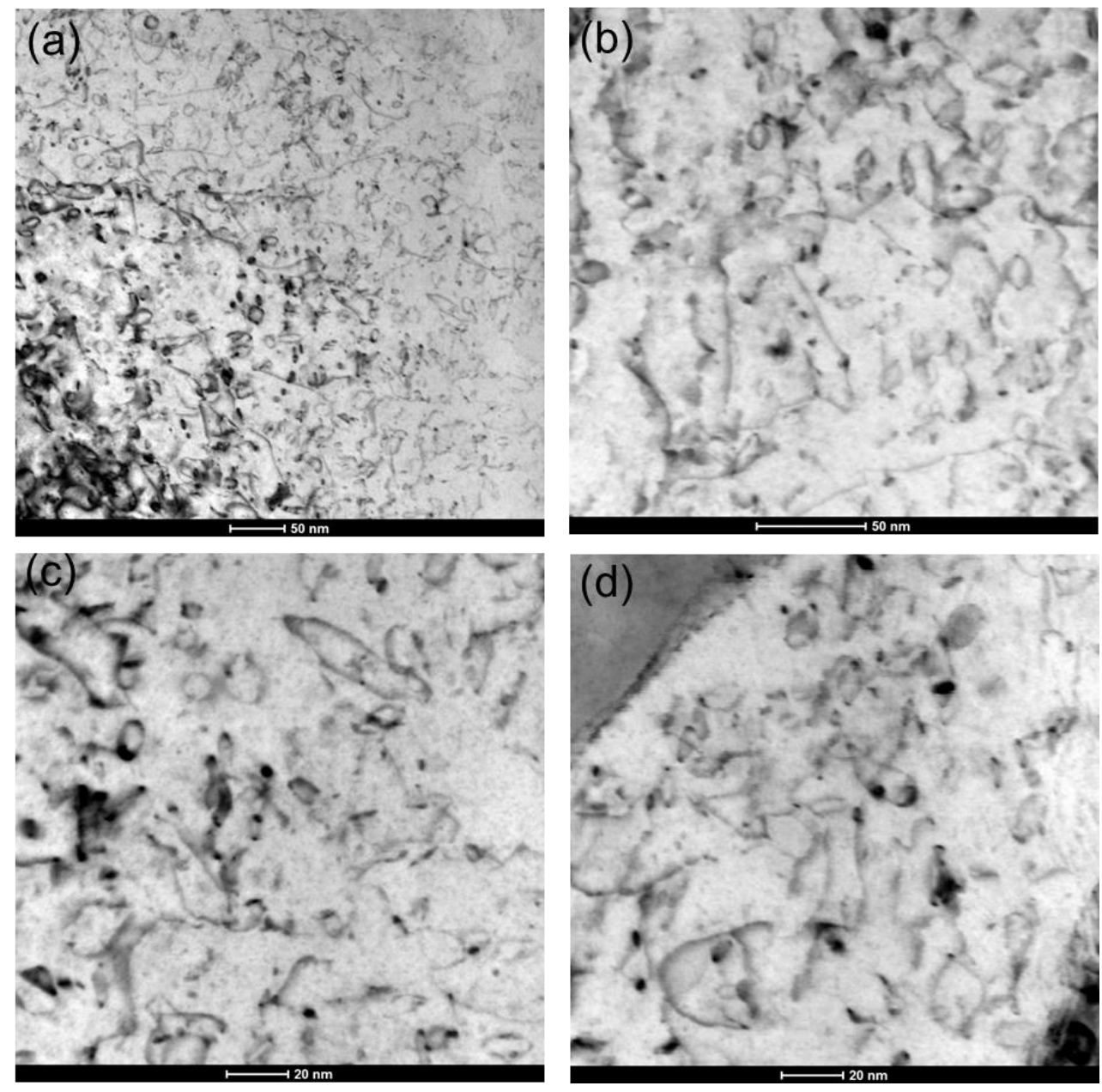

Figure 4: STEM-BF images of dislocation loops recorded at different locations and at different magnifications in the irradiated K series steel. Imaging was performed close to [101] and [100] zone axis using $<110>$ type diffraction vectors.

\subsubsection{H series steels: KIT}

As revealed in Ref. [1], in nonirradiated state TEM/STEM characterization of $\mathrm{H}$ series steel had revealed that two types of precipitate families: (i) predominantly $\mathrm{Ta}, \mathrm{V}$ and $\mathrm{N}$ rich precipitates which are expected to be the MX precipitates and (ii) predominantly $\mathrm{Cr}, \mathrm{W}$ rich phases, which are expected to be $\mathrm{M}_{23} \mathrm{C}_{6}$ carbides. Because all the strong carbide formers typically enter $\mathrm{M}_{23} \mathrm{C}_{6}$ phase, these particles also showed presence of Ta and V. For convenience, the STEM-EDX mapping result from the unirradiated $\mathrm{H}$ series steel are shown in Figure 5 where the two types of precipitate families can be identified. After irradiation, STEM-EDX mapping was again performed on a FIB foil and the results are shown in Figure 6 and Figure 7. These images revealed no significant change in the precipitate structure, because similar $\mathrm{Cr}$, $\mathrm{W}$ rich large precipitates expected to be $\mathrm{M}_{23} \mathrm{C}_{6}$ phase and Ta, $\mathrm{V}$ rich precipitates that are expected to be $\mathrm{MX}$ phase were identified. Except for the elements present in the alloy, no other elements, that may arise from transmutation, were detected. The precipitates after irradiation remained crystalline. This was proven by selected area electron diffraction (SAED). An example of this SAED is given in Figure 8 where crystalline diffraction spots originating from a precipitate on a grain boundary were observed. Upon indexing this SAED, the precipitate phase was identified to be $\mathrm{M}_{23} \mathrm{C}_{6}$. 

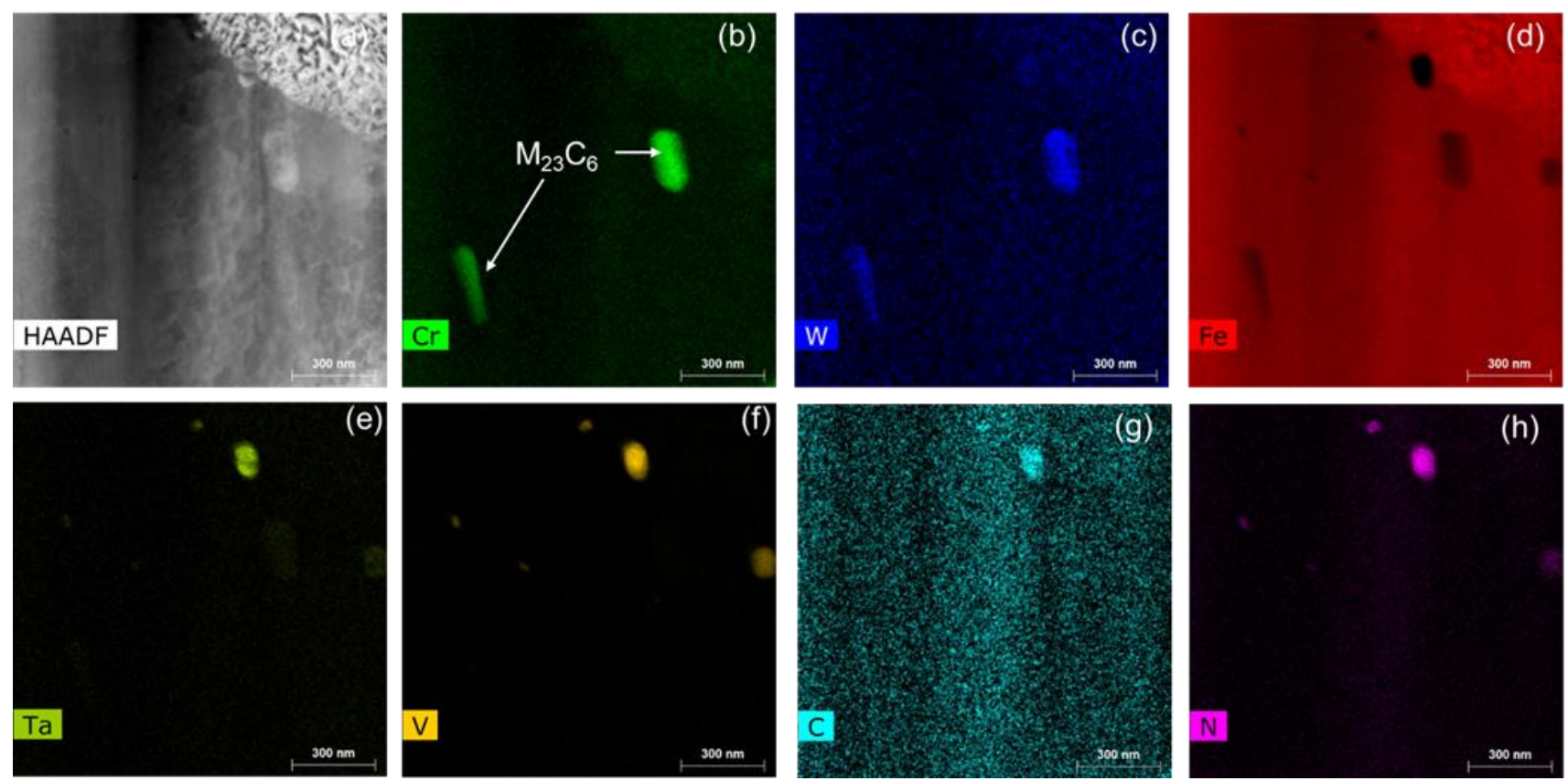

Figure 5: EDX mapping in STEM mode for $\mathrm{H}$ series in nonirradiated condition. (a) HAADF image. (b-h) Elemental maps.
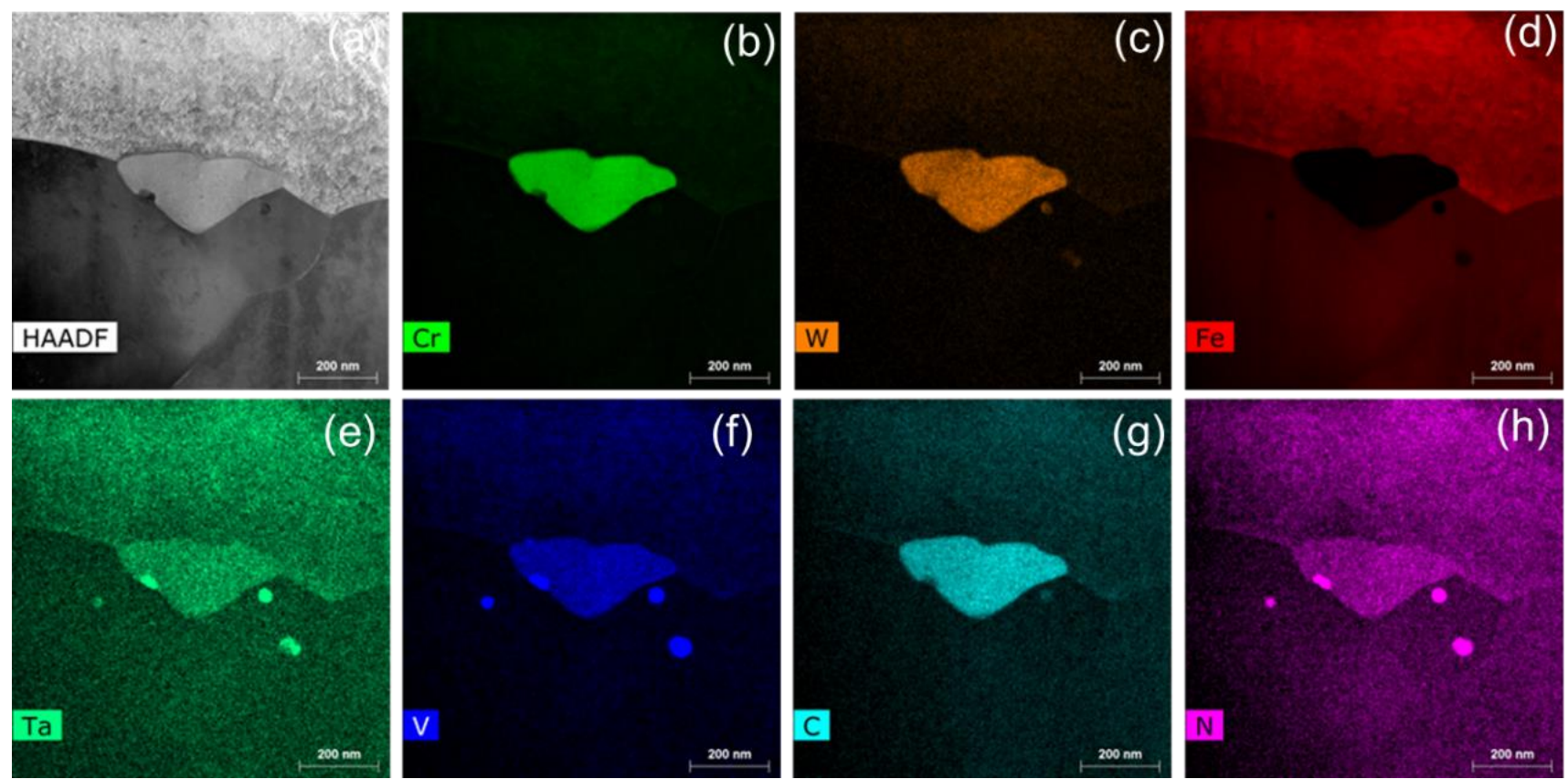

Figure 6: EDX mapping in STEM mode for $\mathrm{H}$ series after irradiation. (a) HAADF image. (b-h) Elemental maps. 

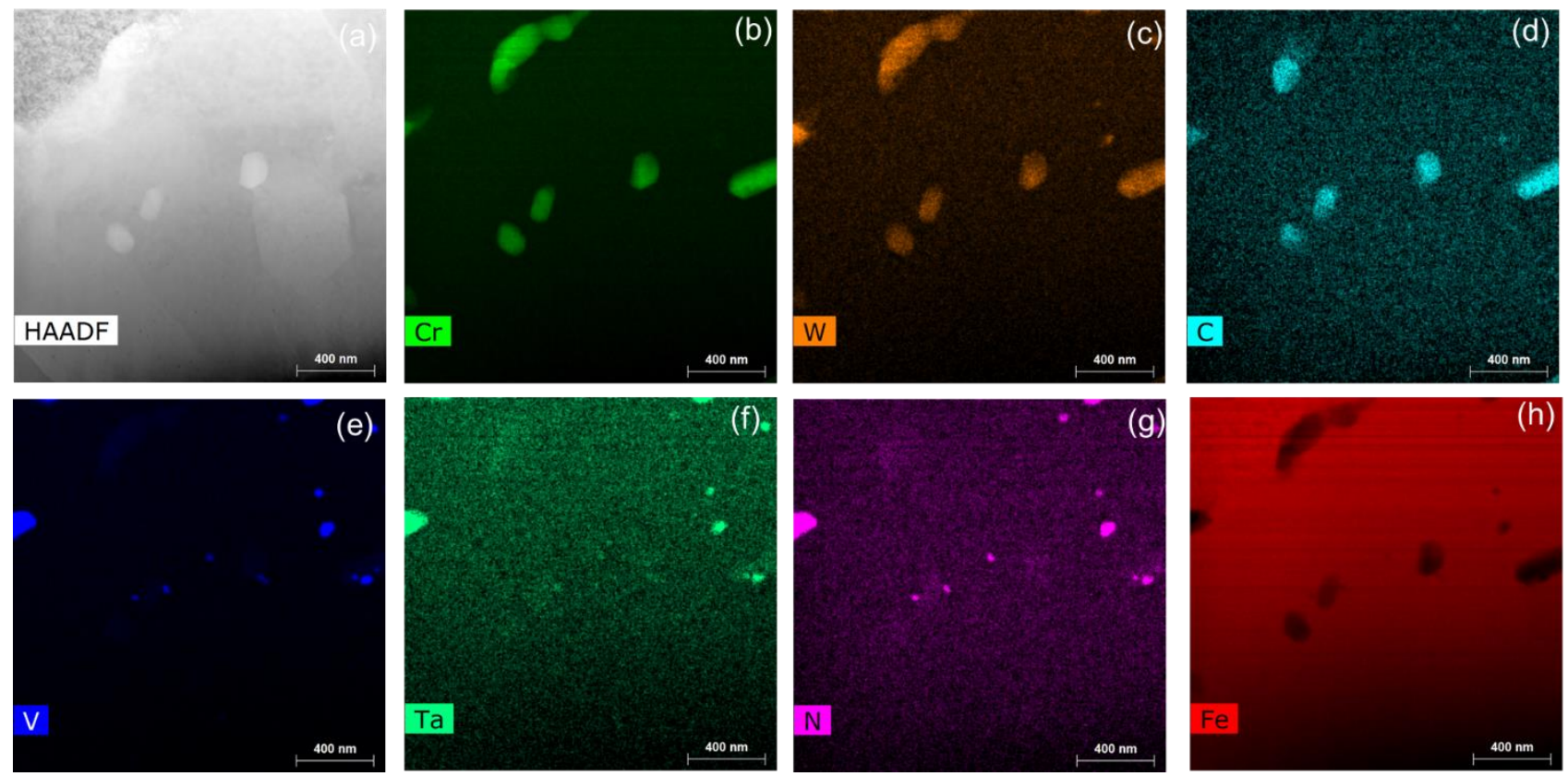

Figure 7: EDX mapping in STEM mode for $\mathrm{H}$ series after irradiation. (a) HAADF image. (b-h) Elemental maps, different zone.
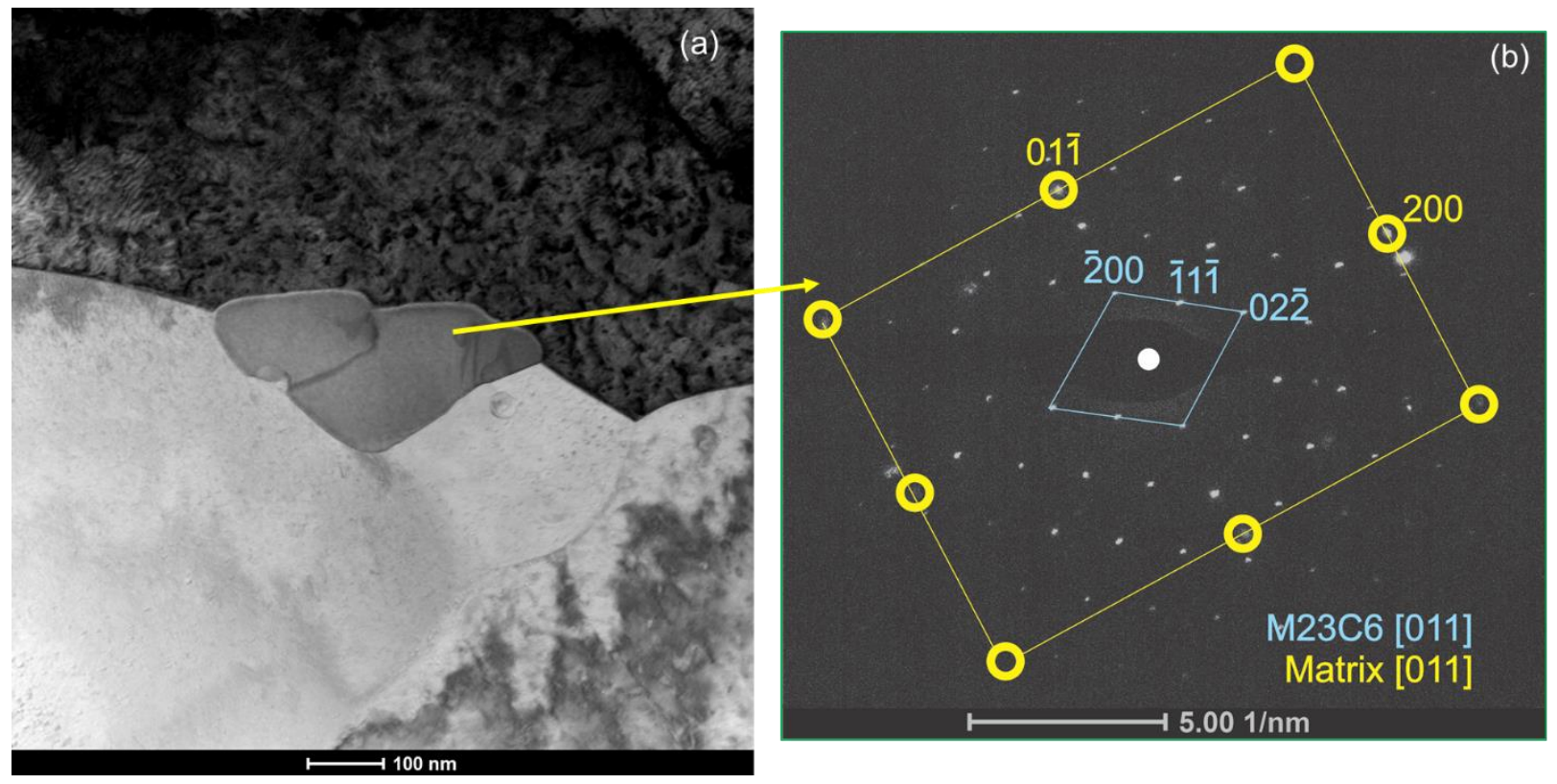

Figure 8: (a) Precipitate on a grain boundary identified as $\mathrm{M}_{23} \mathrm{C}_{6}$ phase in irradiated $\mathrm{H}$ series steel. (b) Indexed SADP revealing the crystallinity and orientation relationship of the precipitate. 
Further, STEM-EDX analysis also revealed some pure $\mathrm{Cr}$ rich precipitates in the matrix, as shown in Figure 9. Such precipitates were globular, $\sim 2-5 \mathrm{~nm}$ in diameter and without any presence of other elements. We believe these may be radiation-enhanced $\mathrm{Cr}$ rich $\alpha^{\prime}$ phase. These precipitates were less numerous and were only observable in certain areas of the sample. Apart from these precipitates, $\mathrm{Cr}$ enriched areas, appearing to form as oval shaped rings were also detected when STEM-EDX was performed at higher magnifications (see Figure 9). We believe this is due to the well-known irradiation-induced segregation of $\mathrm{Cr}$ atoms to dislocation loop cores. Atom probe tomography (APT) would be needed to quantify this phenomenon.

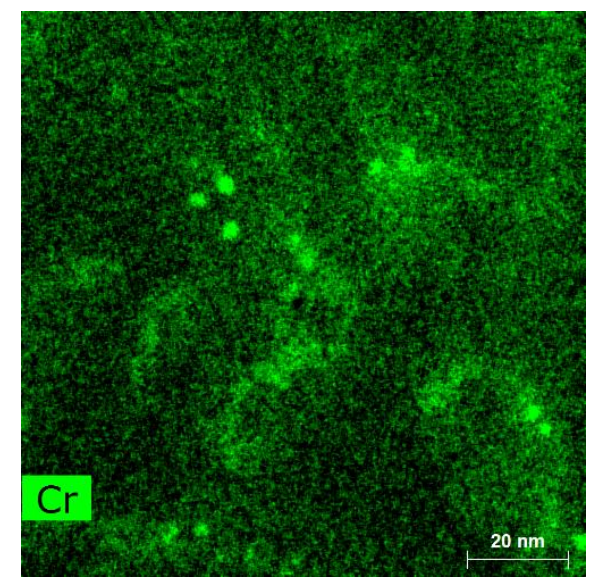

Figure 9: Cr rich globular precipitates and $\mathrm{Cr}$ enriched oval/ring type areas in the irradiated $\mathrm{H}$ series steel. No other elements were detected here other than $\mathrm{Cr}$.

STEM imaging revealed irradiation-induced dislocation loops in this steel. The corresponding BF and LAADF images, obtained close to [101] zone axis, are given in Figure 10. Some of the identified dislocation loops are encircled in the LAADF image. These dislocation loops were mostly black-dot type with an average diameter of $\sim 3 \mathrm{~nm}$ and number density of $1.2 \times 10^{21} \mathrm{~m}^{-3}$. Such small loops are remarkably different to the results obtained in the K series steel where the average loop size was much larger, at $11 \mathrm{~nm}$. Here, one must be cautious that the loop sizes in $\mathrm{H}$ series steel are very close to those expected from FIB damage. Therefore, more analysis on flashed polished samples is suggested as a future study.
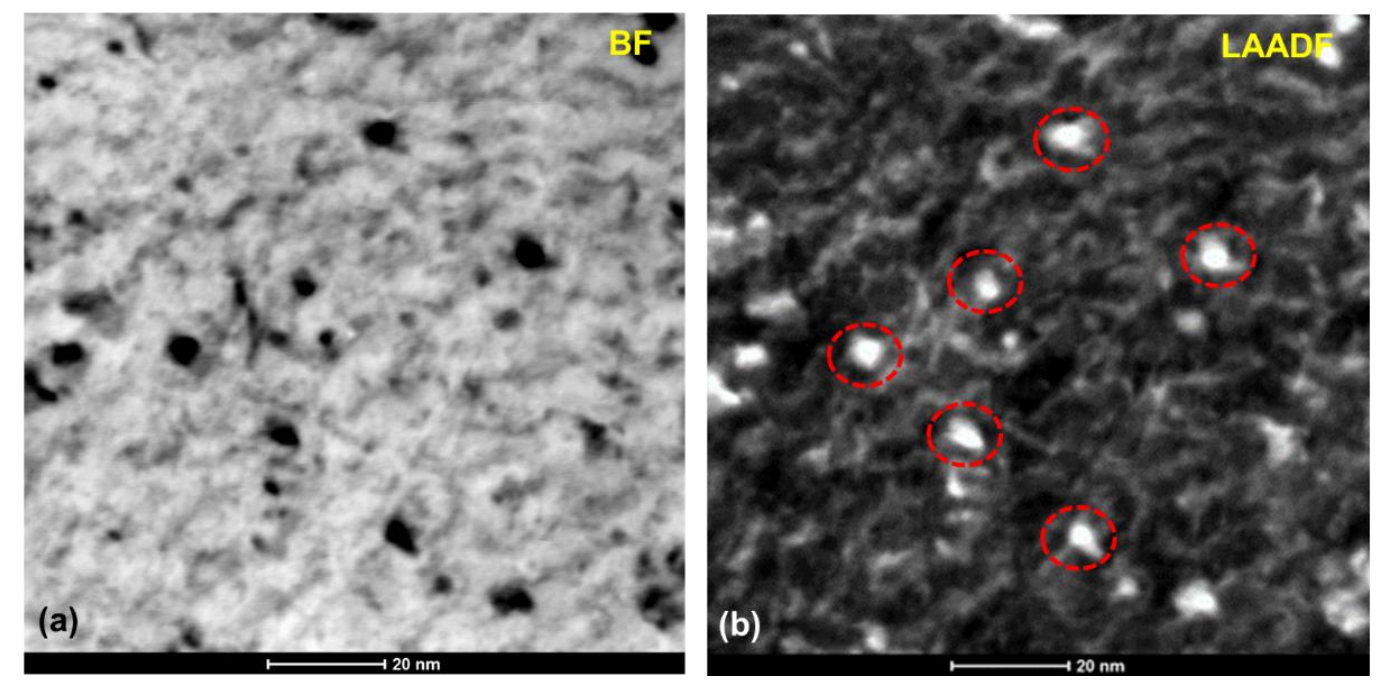

Figure 10. Dislocation loops in H series steel imaged close to [101] zone axis in (a) STEM-BF mode and (b) LAADF mode. Some loops are encircled in (b). 


\subsubsection{I series steels: KIT}

Similar to the $\mathrm{H}$ series steel, I series steel in the nonirradiated condition also showed the presence of primarily two types of precipitate phases: $\mathrm{Cr}, \mathrm{W}$ rich larger carbides on the grain/lath boundaries that are expected to be $\mathrm{M}_{23} \mathrm{C}_{6}$ type and Ta, V rich smaller precipitates that are expected to be the MX phases. HAADF STEM image and associated EDX elemental maps from this steel in the nonirradiated form are shown in Figure 11.
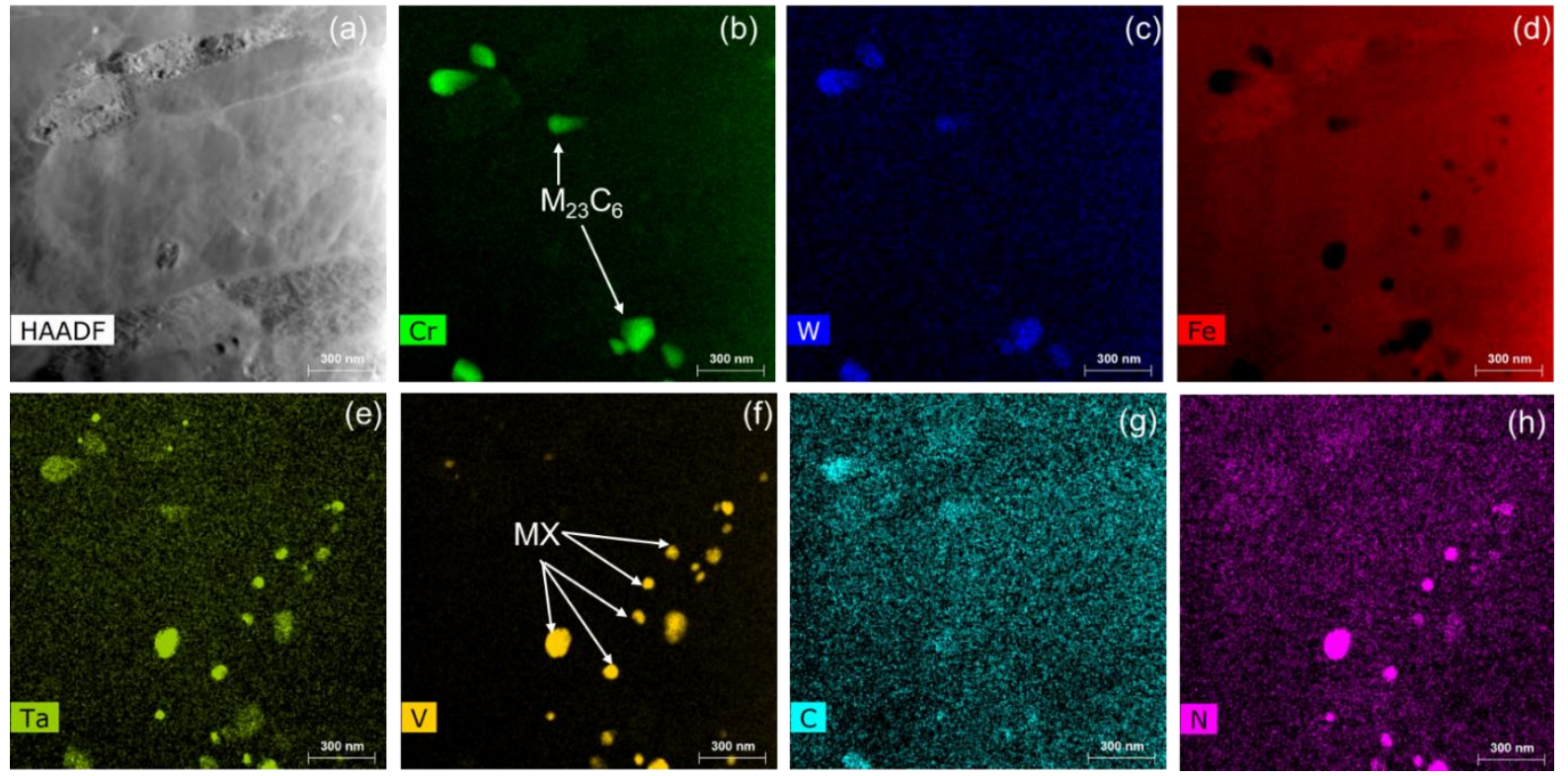

Figure 11: EDX mapping in STEM mode for nonirradiated I series steel. (a) HAADF image. (b-h) Elemental maps.

After irradiation, similar EDX mapping was performed to see if any qualitative difference existed or not. The corresponding HAADF image and EDX mapping from the irradiated steel are given in Figure 12. Similar to the case of the nonirradiated alloy, evidence of $\mathrm{Cr}$ rich larger $\mathrm{M}_{23} \mathrm{C}_{6}$ precipitates and $\mathrm{V}$, Ta rich smaller precipitates were detected, with no apparent qualitative differences.

An interesting observation in the I series steels was that numerous precipitates were identified in the matrix that showed damaged structures caused by the neutron irradiations. These precipitates consisted of complex sponge-like sub-structures revealed by imaging in STEM mode. Two examples of such precipitates in the matrix are provided in Figure 13. where HAADF imaging revealed the intricate structural morphology within these precipitates. In these figures, we believe the much darker regions are internal holes created by the irradiation inside these precipitates. To reveal the chemistry of these precipitates, EDX mapping in STEM more was performed. This revealed two kind of sponge like precipitates: (i) the first one being $\mathrm{Fe}, \mathrm{Cr}, \mathrm{C}$ rich as shown in Figure 14. No evidence of other elements was detected in these sturtcures. Here, undulations in the distribution of Fe can be seen which corresponds well with the dark regions in the LAADF image. We believe these dark regions are perhaps nano-cavities/holes formed inside this precipitate. Because the particle was enriched in $\mathrm{Fe}, \mathrm{Cr}, \mathrm{C}$, we believe this phase is $\mathrm{M}_{23} \mathrm{C}_{6}$ that suffered degradation due to irradiation. Another set of detected particles that showed the sponge-like structure are shown in Figure 15, where we reveal that this phase was V, W and $\mathrm{O}$ rich, and hence implies is an oxide phase. These oxide phases were not detected in the nonirradiated I series steel and imply that these precipitates may have formed under the irradiation. What is puzzling is that $\mathrm{Cr}$ has strong affinity towards $\mathrm{O}$. However, despite these precipitates rich in $\mathrm{O}$, there was no presence of $\mathrm{Cr}$. These results are qualitatively 
similar to the recent results produced at ORNL on the evolution of coarse oxide particles in ODS alloy irradiated to $>60 \mathrm{dpa}$ by neutrons in HFIR at $\sim 300{ }^{\circ} \mathrm{C}$. A mechanism of this peculiar phenomenon is not fully understood and requires a dedicated effort.
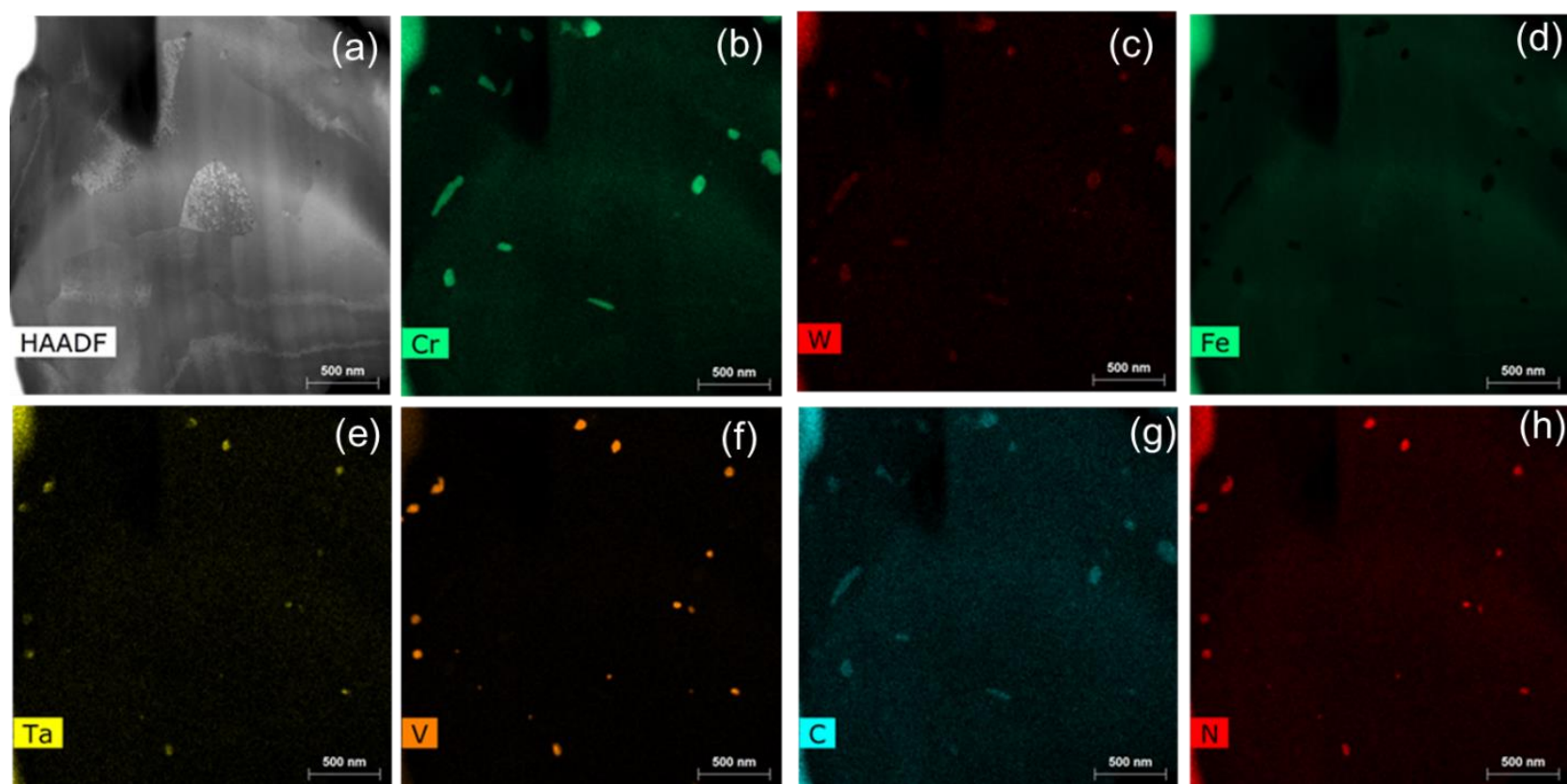

Figure 12 EDX mapping in STEM mode for irradiated I series steel. (a) HAADF image. (b-h) Elemental maps, second FIB foil.
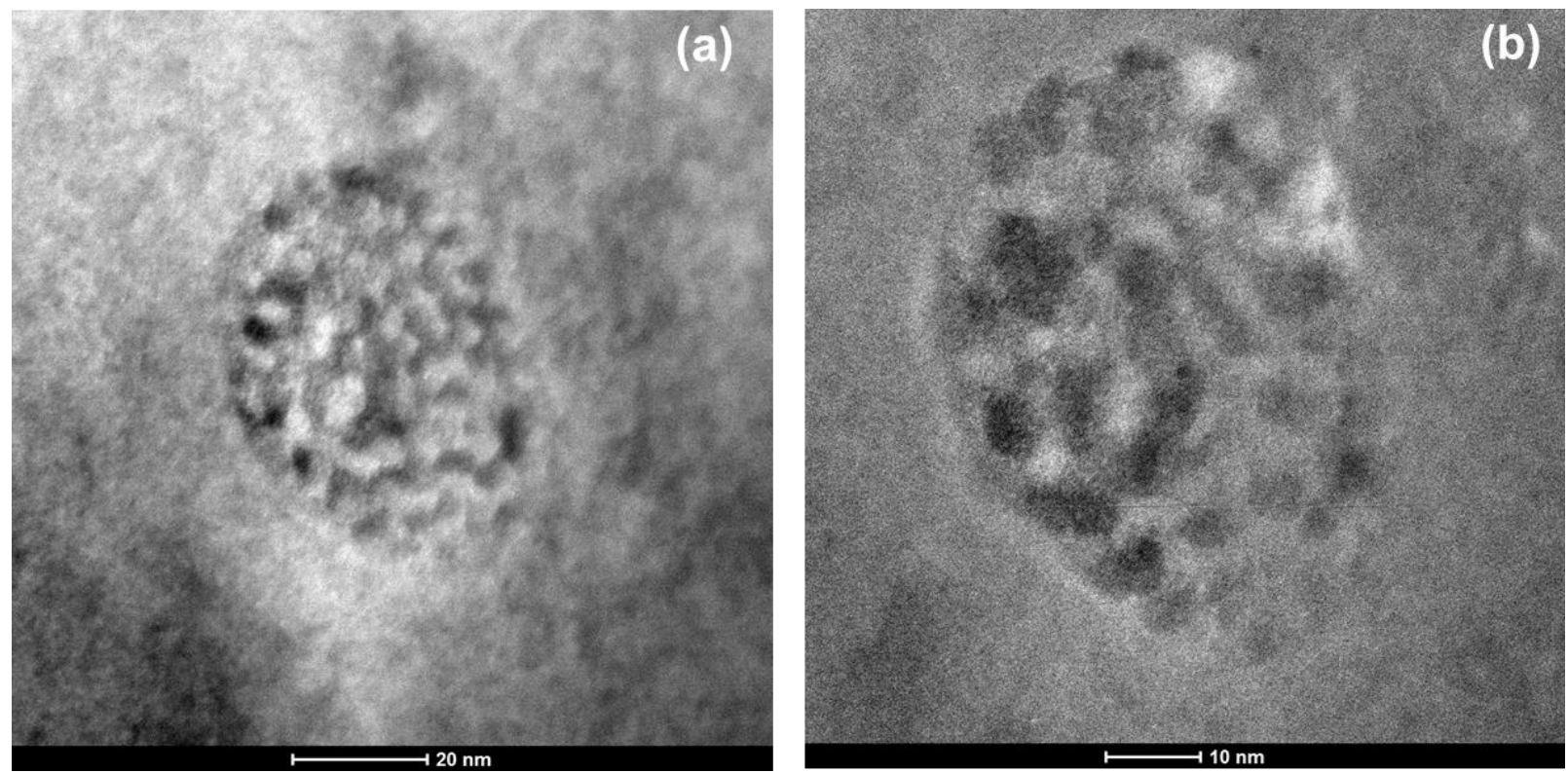

Figure 13: HAADF images of complex sponge-like precipitates in the neutron irradiated I series steel. 

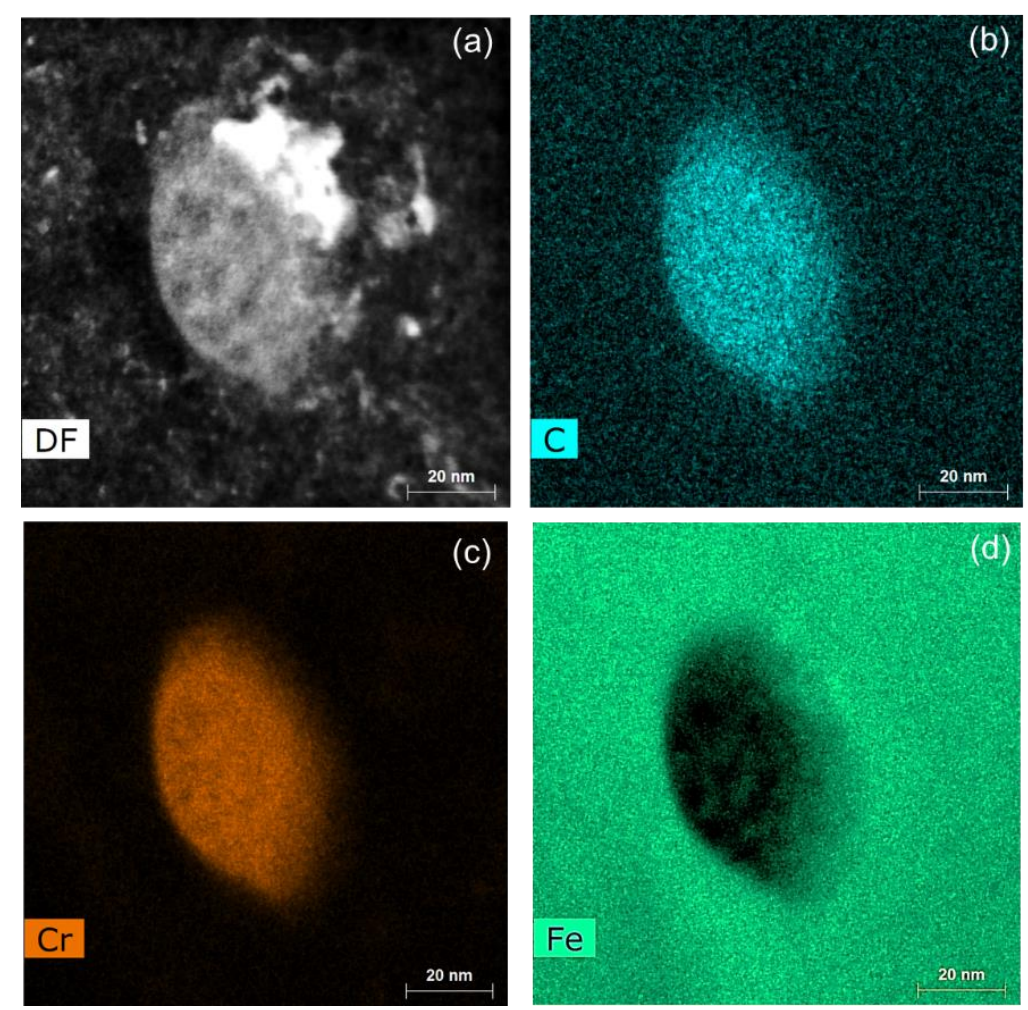

Figure 14: Fe, Cr, C rich sponge like precipitates in irradiated I series steel. (a) MAADF image and (b-d) are elemental maps.
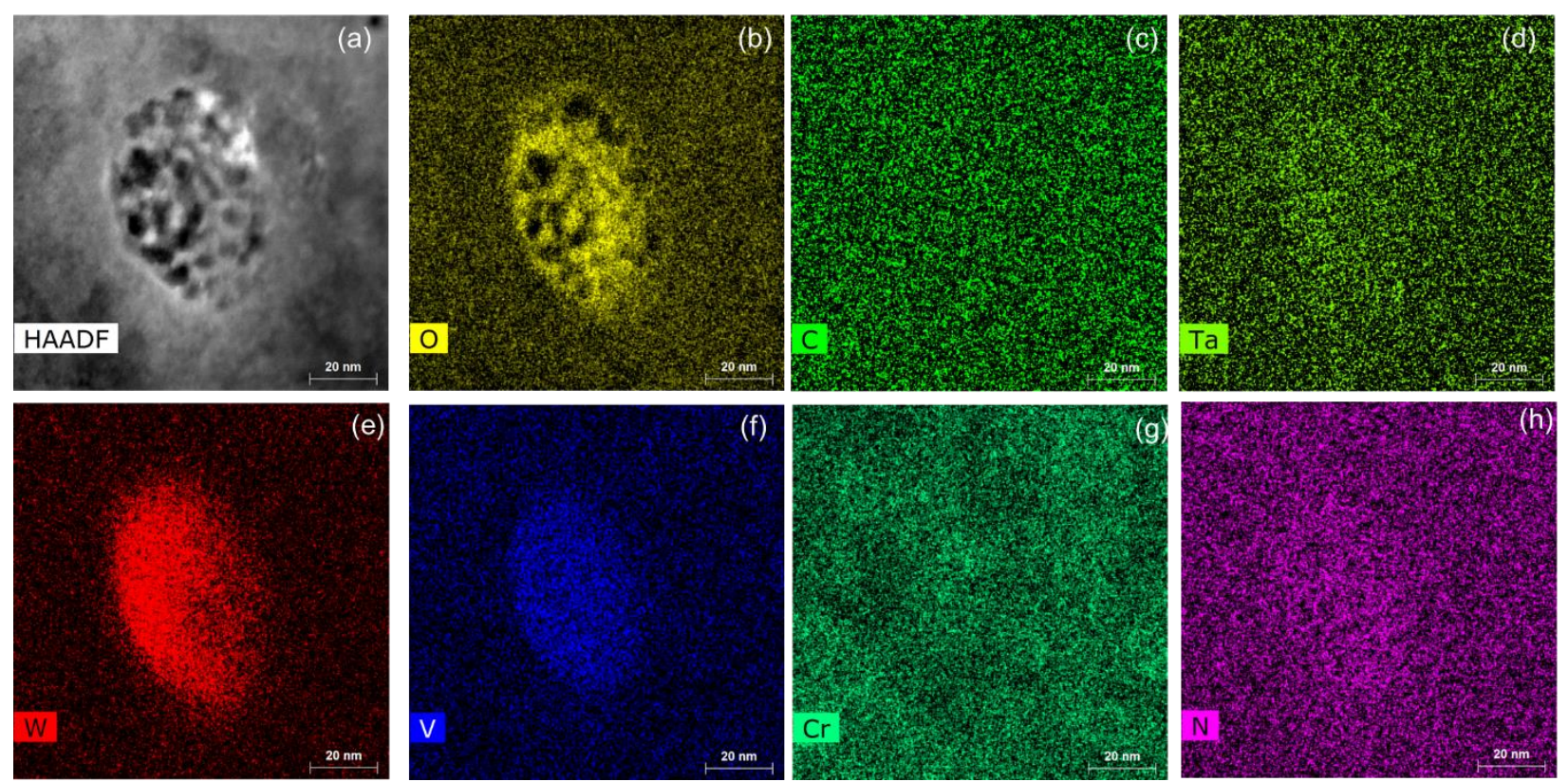

Figure 15: O, W, V rich sponge-like precipitates in irradiated I series steel. 
After performing analytical analysis of the secondary phases, STEM imaging was used to study the irradiation induced extended defects. For example, Figure 16 reveals that the dislocation loops were like black-dot type damage, very small between $\sim 2-10 \mathrm{~nm}$ in diameter. Certain identified dislocating loops are encircled in Figure 16. The number density of these black dot defects was $2.3 \times 10^{21} \mathrm{~m}^{-3}$.
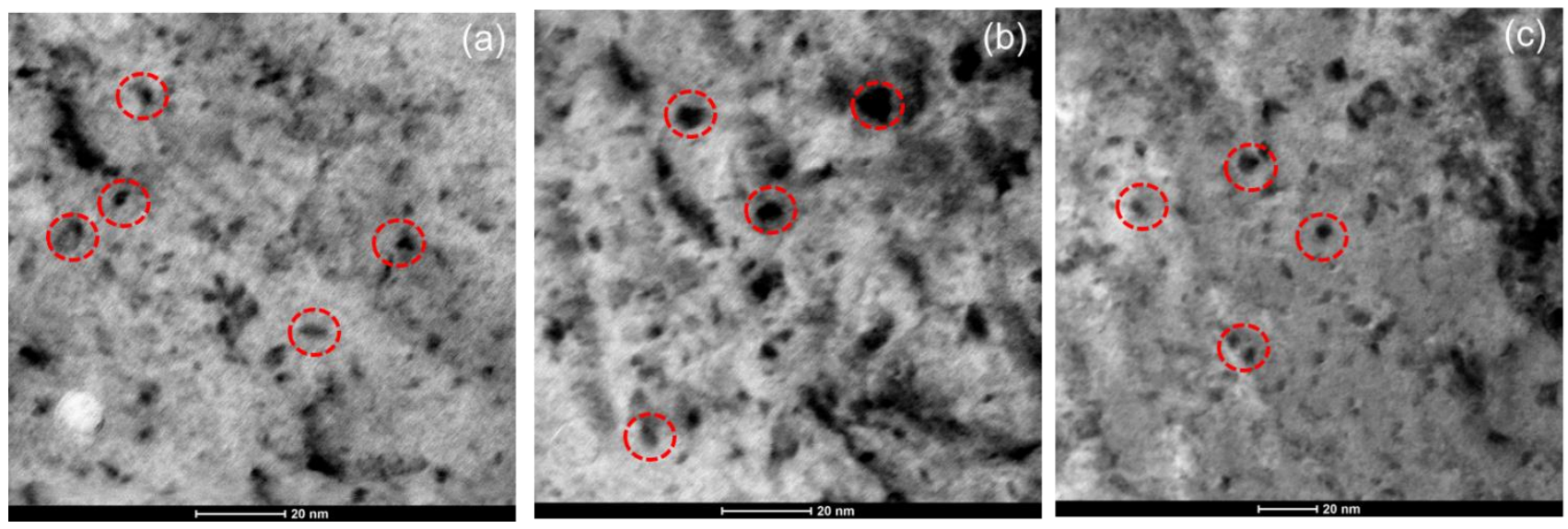

Figure 16: BF STEM images of black-dot type dislocation loops in irradiated I series steel. Imaged close to [101] zone axis. Encircled are certain black-dot type defects identified in the matrix. Zone axis $=[101]$, $\mathrm{g}=\langle 110>$ type.

No presence of purely $\mathrm{Cr}$ rich phase, as detected for the $\mathrm{H}$ steel, was observed in this steel.

\subsubsection{P series steels: KIT}

In nonirradiated condition, $\mathrm{P}$ series steel also consisted of Ta, $\mathrm{V}$ rich precipitates (MX phase) and $\mathrm{Cr}$, W rich large $\mathrm{M}_{23} \mathrm{C}_{6}$ carbides. HAADF image and STEM-EDX maps from the nonirradiated sample are given in Figure 17.
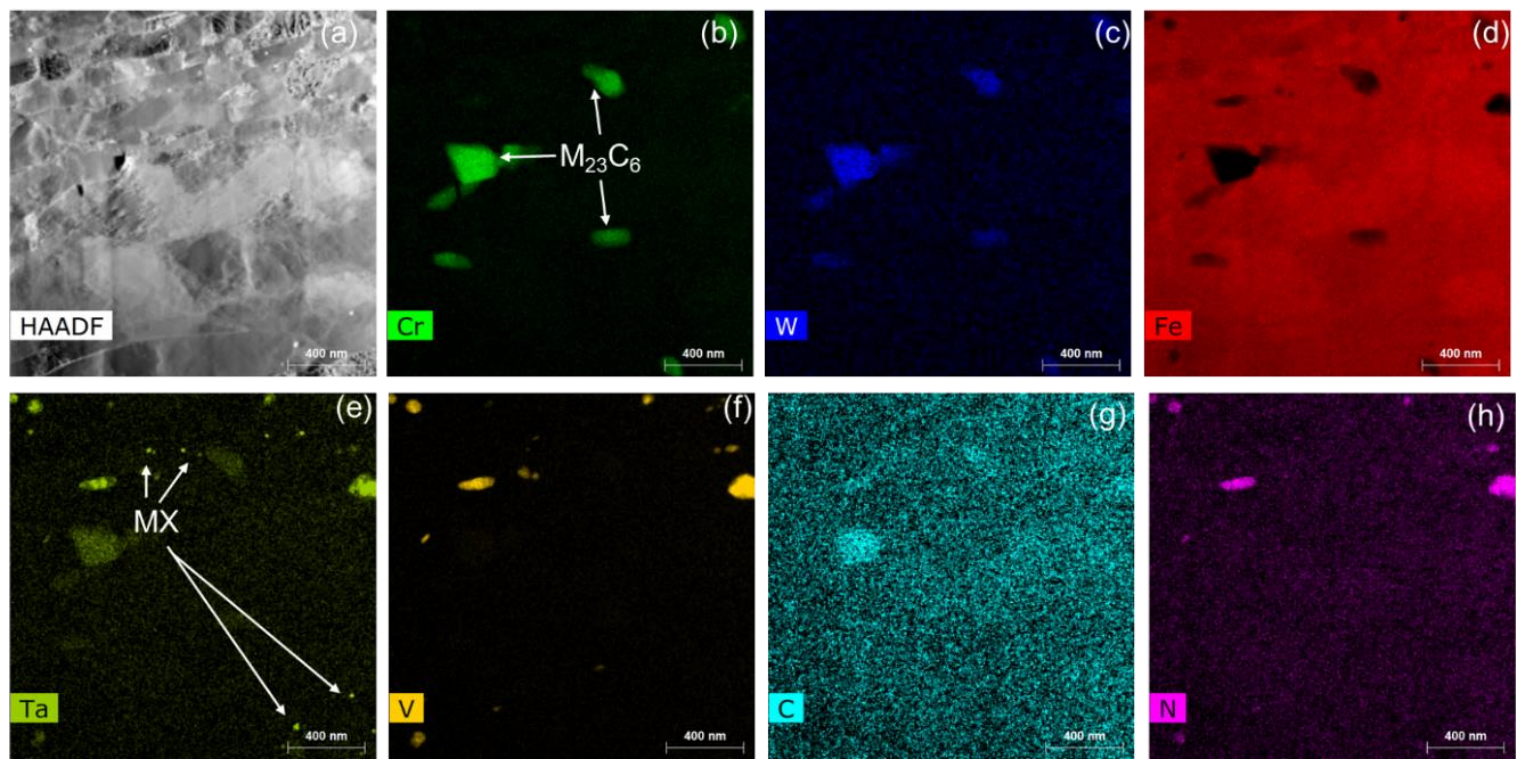

Figure 17: EDX mapping in STEM mode for nonirradiated P series steel. (a) HAADF image. (b-h) Elemental maps. 
After irradiation, the presence of $\mathrm{M}_{23} \mathrm{C}_{6}$ and $\mathrm{MX}$ phases was confirmed in the microstructure; no significant precipitate evolution occurred (Figure 18). Further, no sponge-like precipitate evolution, as detected in the I series steel, was observed in this alloy. EDX map for Cr suggested some segregation onto the grain/lath boundaries, which is expected for an Fe-Cr alloy and an Fe-Cr based FM/RAFM steel. A high magnification HAADF and EDX maps from the irradiated steel are shown in Figure 62 where, except for the $\mathrm{Cr}$ rich $\mathrm{M}_{23} \mathrm{C}_{6}$ phase, no evidence of $\mathrm{Cr}$ clustering in the matrix as seen for $\mathrm{H}$ series steel, was detected.
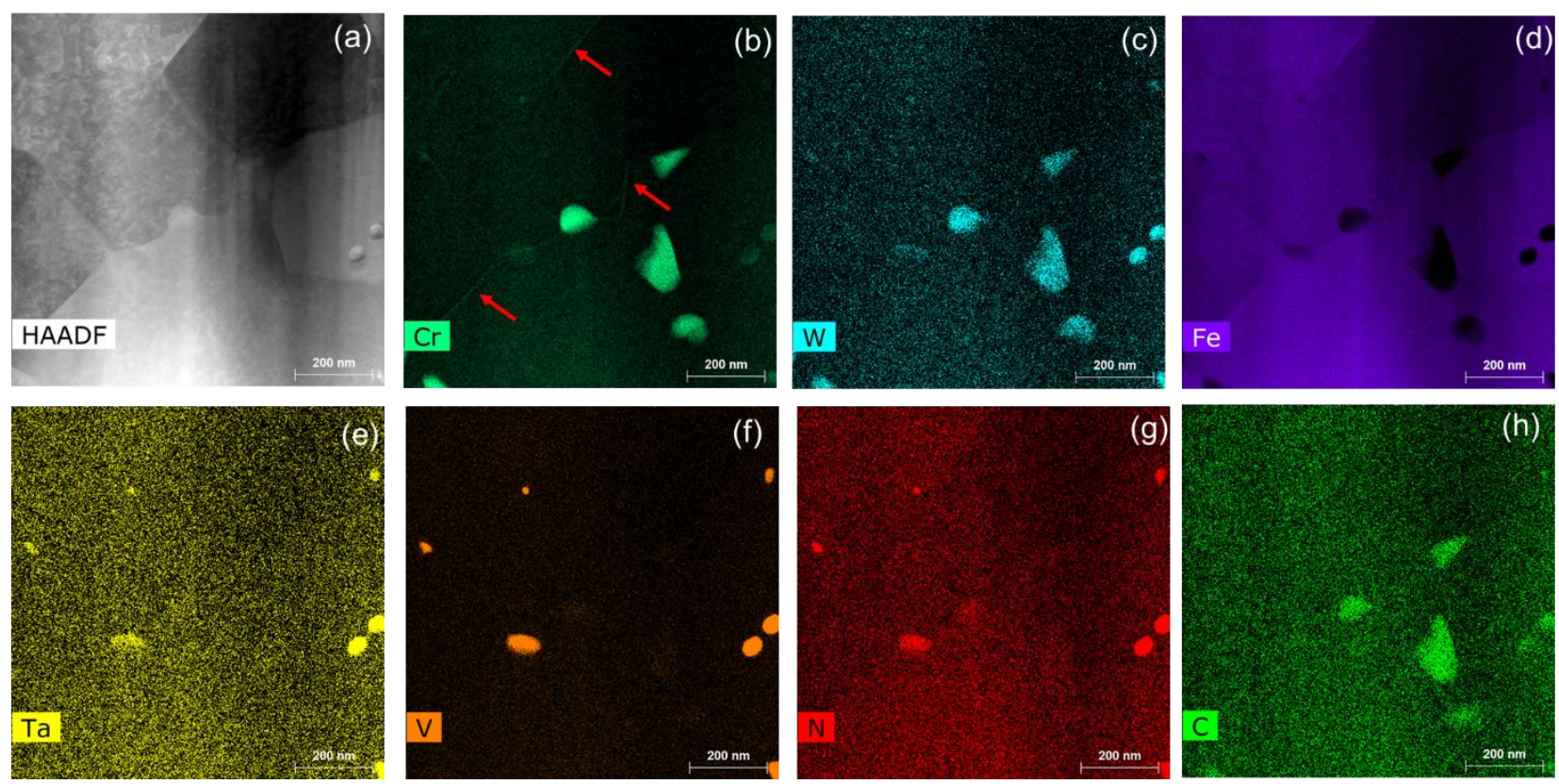

Figure 18: EDX mapping in STEM mode for irradiated P series. (a) HAADF image. (b-h) Elemental maps.

When imaged in STEM-BF mode, dislocation loops created by the neutron irradiations were revealed in the microstructure. A few examples of such loops, observed at different regions of the foil and at differing magnifications, are provided in Figure 63 where some are encircled. In many cases, these loops appeared close to on-edge configuration and generated the typical coffee-bean contrast (Figure 19). All these images were recorded close to [101] zone axis. The average diameter and number density of the dislocation loops was $6.7 \mathrm{~nm}$ and $5.5 \times 10^{20} \mathrm{~m}^{-3}$. Once again, the microstructure is quite complicated with numerous features appearing in the size range of FIB damage. 

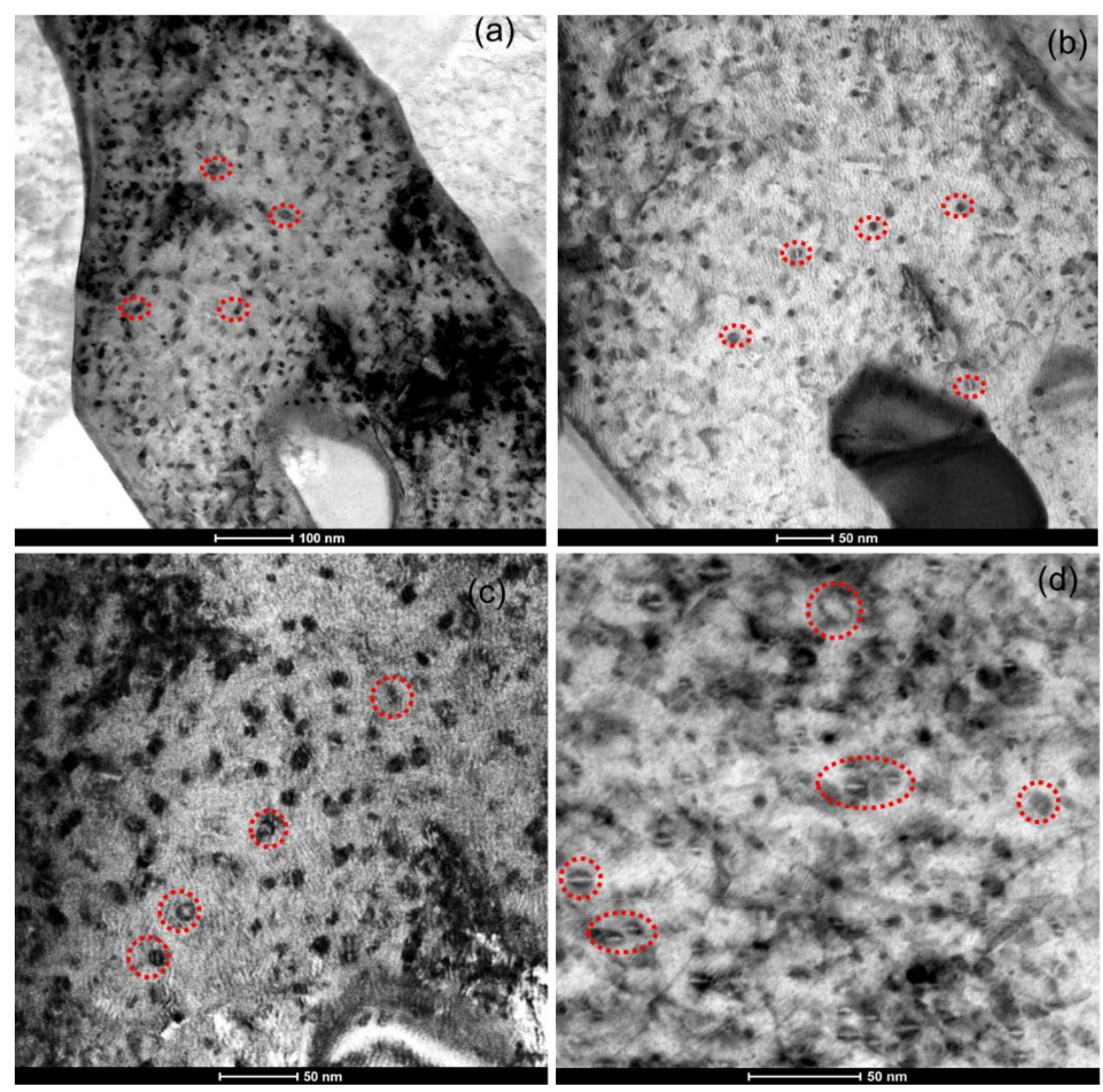

Figure 19: STEM-BF images revealing the dislocation loops in irradiated P series steel. Imaging performed close to [101] zone axis, in down axis condition. Many identified dislocation loops are encircled.

\subsubsection{J series steels: SCK-CEN}

Figure 20 presents BF TEM/STEM and MAADF images of the microstructure of J series steel. In all these figures the laths can be identified with typical large precipitates. Precipitates were better resolved in the MAADF images (indicated using yellow arrows). To better distinguish the $\mathrm{M}_{23} \mathrm{C}_{6}$ and MX phases, EDX mapping was performed in STEM mode (see Figure 21). Large precipitates (> $50-80 \mathrm{~nm}$ ) were $\mathrm{Cr}$, W rich and are expected to be $\mathrm{M}_{23} \mathrm{C}_{6}$, while smaller precipitates $(<30 \mathrm{~nm})$ where $\mathrm{Ta}, \mathrm{V}$ and $\mathrm{N}$ rich consistent with MX phases.

After irradiation, no significant degradation or changes to the precipitate microstructure was detected. Further, no sponge like transformation of the carbides, as seen for material I was observed. Figure 22 presents an overview of the precipitate microstructure after irradiation, imaged in STEM-EDX mode where the coarse $\mathrm{M}_{23} \mathrm{C}_{6}$ and $\mathrm{V}$ rich $\mathrm{MX}$ phases can be seen. Selected area electron diffraction pattern recorded 
from the $\mathrm{M}_{23} \mathrm{C}_{6}$ carbide shows that these phases remained fully crystalline after the irradiation, with no evidence of any amorphization.
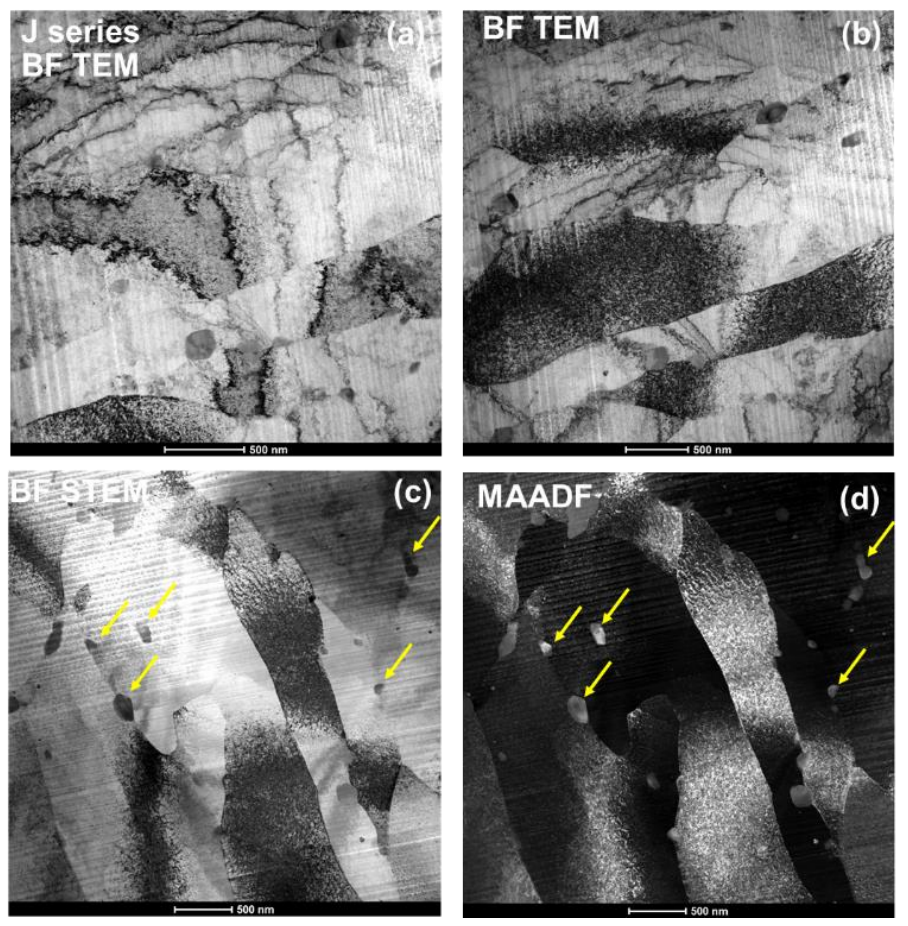

Figure 20: TEM and STEM imaging of J series steel. (a,b) Conventional BF TEM images, (c, d) BF STEM and MAADF image of the same zone.

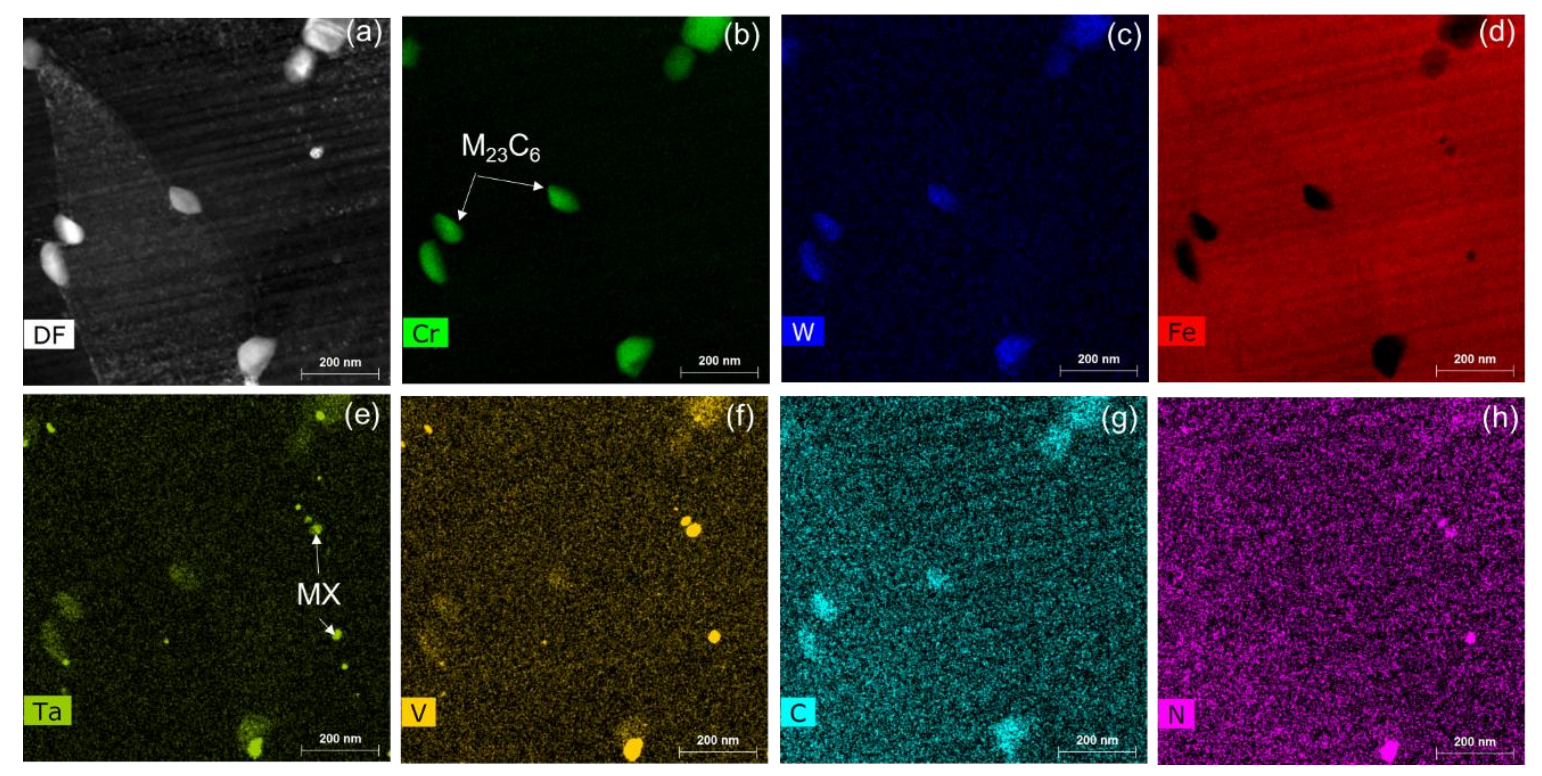

Figure 21: EDX mapping in STEM mode for J series. (a) MAADF image. (b-h) Elemental maps. 

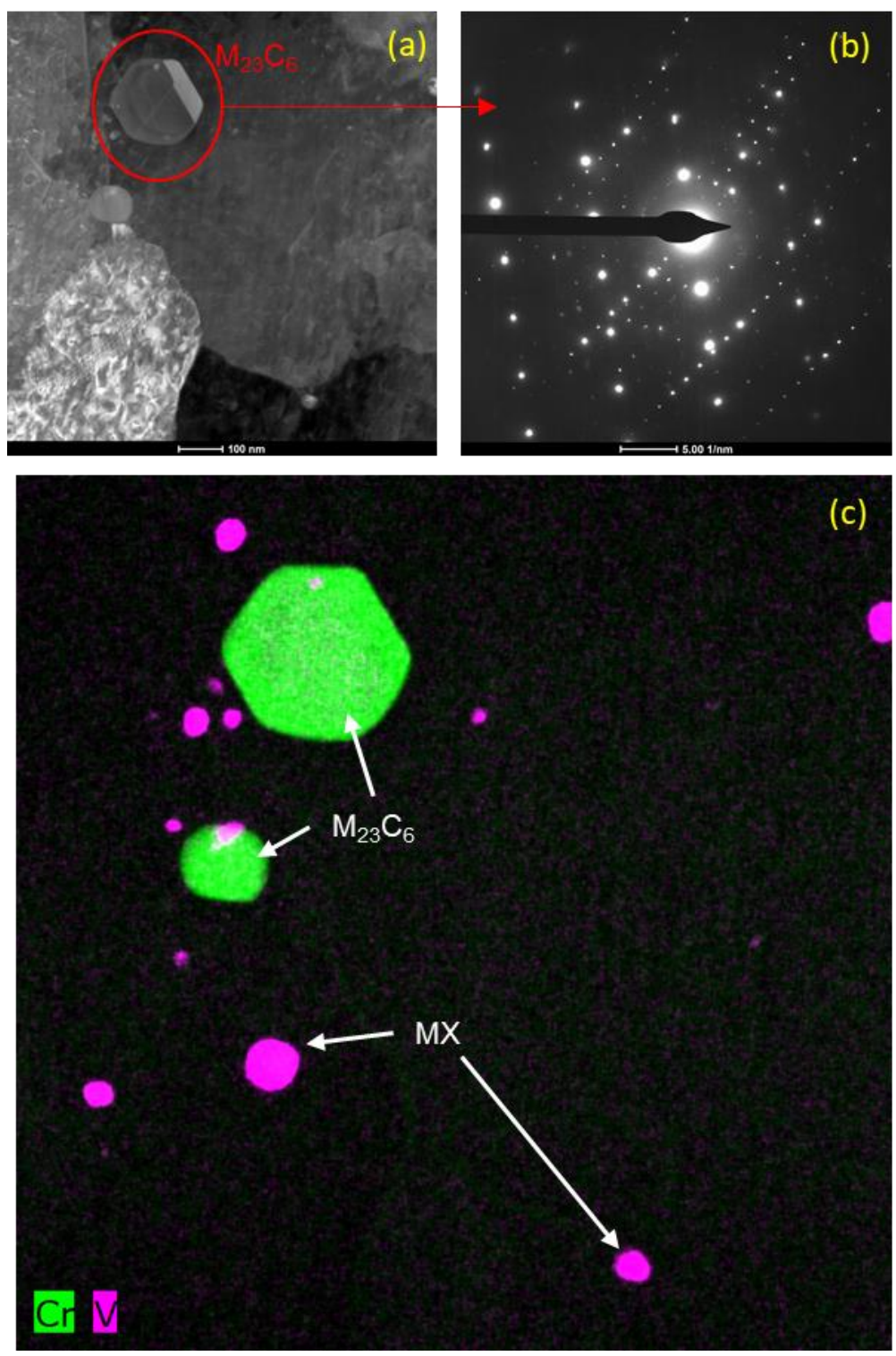

Figure 22: Characterization of precipitates in material $\mathbf{J}$ after irradiation. (a) STEM-MAADF image of a zone containing $\mathrm{M}_{23} \mathrm{C}_{6}$. (a) SAED pattern of the $\mathrm{M}_{23} \mathrm{C}_{6}$ carbide showing crystallinity. (c) STEM EDX Cr and $\mathrm{V}$ map over lay to show the distribution of $\mathrm{M}_{23} \mathrm{C}_{6}$ carbides and $\mathrm{MX}$ carbonitrides.

Extended defects such as dislocation loops formed in this alloy due to irradiation. Figure 23a presents an overview of the FIB foil where a grain close to diffraction conditions with visible defect contrast is presented. When the same grain was magnified and imaged close to [001] axis, dislocation loops were clearly identified. While performing g.b analysis on the nanometric grains is challenging, the Burgers vector of the loops can be inferred based on the selected diffraction condition and zone axis. In Figure 23b, the loops appearing on-edge aligned along [010] or [001] directions were a $<100>$ type dislocation loops while all the other loops that were not on-edge were $a / 2<111>$ type. This shows that $a<100>$ type loops form in RAFM steels at temperatures as low as $300{ }^{\circ} \mathrm{C}$, that contradicts decades of data produced in $\mathrm{Fe}-\mathrm{Cr}$ alloys and FM steels by ion irradiations. Figure $23 \mathrm{c}$ and $\mathrm{d}$ present different areas of the foil imaged in MAADF and $\mathrm{BF}$ conditions where the overview of the dislocation loop microstructure can be seen. Figure $23 \mathrm{~d}$ shows a MAADF image of loops around a large $\mathrm{M}_{23} \mathrm{C}_{6}$ carbide where no apparent loop denuded zone around the 
precipitate is visible. Compared to the previous alloys, the size of loops was larger in material $\mathrm{J}$, with some loops as large as $50-75 \mathrm{~nm}$ and lower number density $\left(0.85 \times 10^{20} \mathrm{~m}^{-3}\right)$.
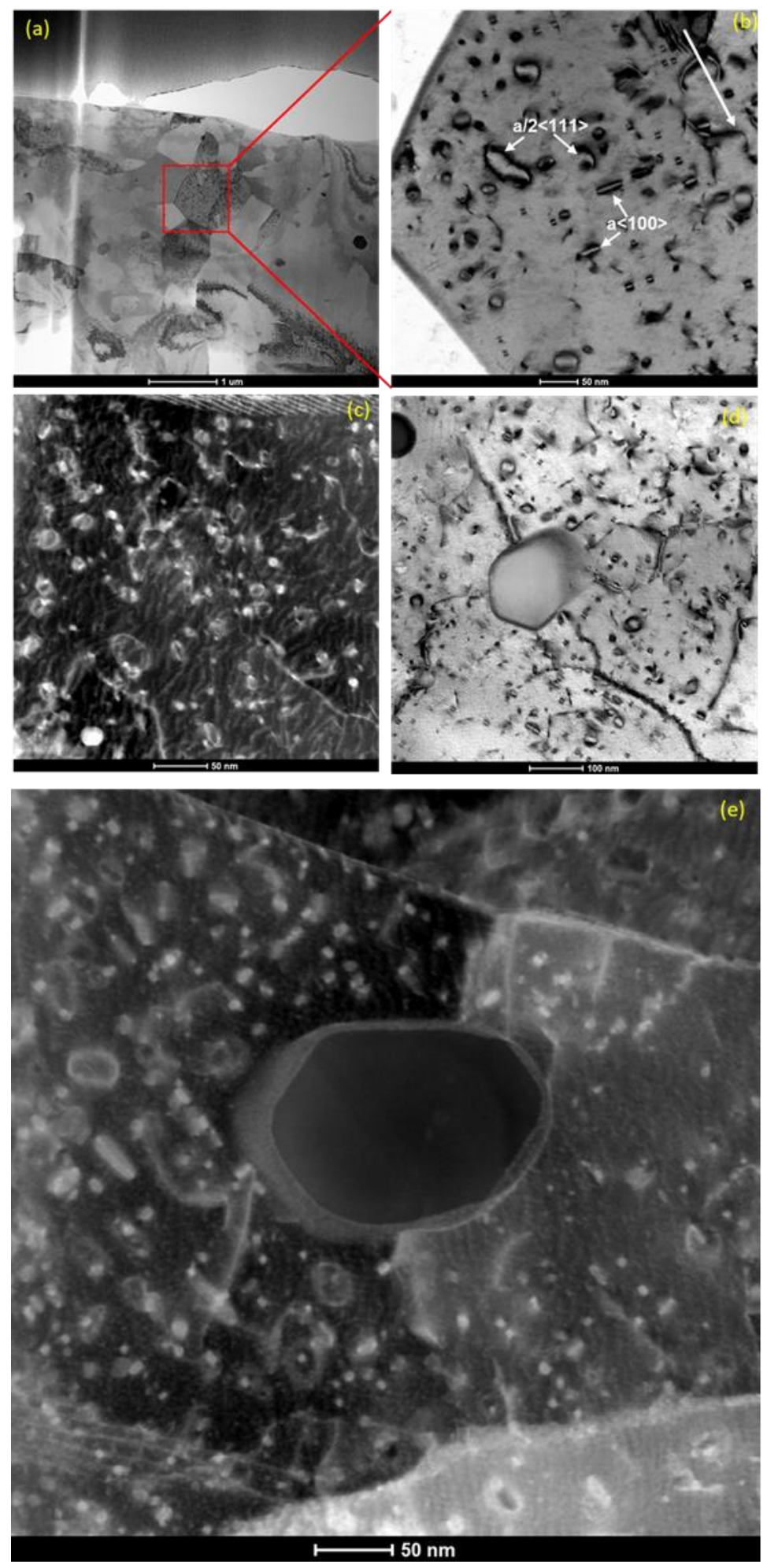

Figure 23: Characterization of dislocation loops in material $\mathrm{J}$ after irradiation. (a) STEM-BF image of the foil overview showing a grain close to [001] zone axis. (b) High magnification image of dislocation loops detected in the highlighted grain in (a) when imaged with (110) type g vector close to [001] zone axis, 
deviation parameter $\mathrm{s}>0$. (c) MAADF image of dislocation loops in a grain. (d) STEM-BF image of dislocation loop distribution around a large $\mathrm{M}_{23} \mathrm{C}_{6}$ carbide. (e) Overview of loop distribution imaged close to [001] zone axis around a large $\mathrm{M}_{23} \mathrm{C}_{6}$ carbide.

\subsubsection{L series steels: CEA}

Figure 24 and Figure 25 show BF and MAADF images of the sample showing the typical lath structure in material L, adapted from Ref. [1]. Large carbides were detected along the lath boundaries, which are expected to be the $\mathrm{M}_{23} \mathrm{C}_{6}$ or $\mathrm{M}_{7} \mathrm{C}_{3}$ type [3]. Some small precipitates were also detected. These precipitates were slightly better visible in the MAADF images compared to BF. These small precipitates have been shown to be mainly $\mathrm{Cr}, \mathrm{V}$ rich $\mathrm{M}_{2} \mathrm{X}$ nitride phase instead of MX carbo-nitrides [3]. Figure 24 was imaged close to 2-beam conditions which brought the high dislocation density of the laths come into contrast. Figure 25 shows a few 5-7 nm size precipitates detected in the steel which can be either $\mathrm{M}_{2} \mathrm{X}$ or MX.
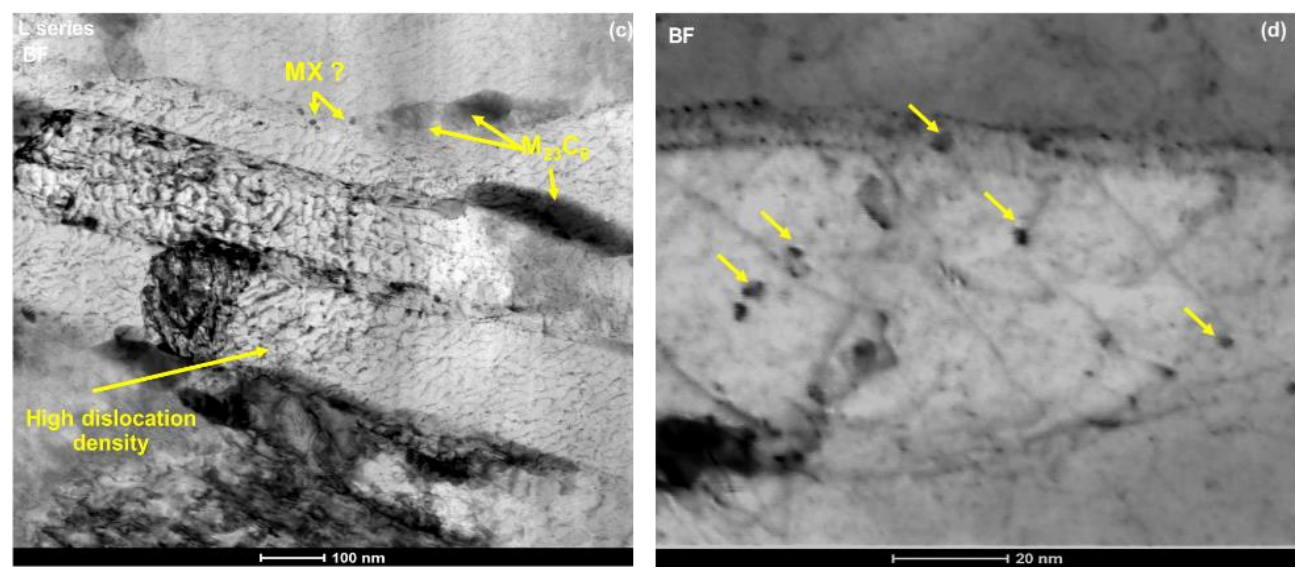

Figure 24: STEM imaging of L series steel. (a, b) BF and MAADF images showing the sample overview, with some precipitates indicated using arrows. (c) BF image close to two beam conditions showing the high dislocation density. (d) High magnification BF STEM image close to two-beam condition revealing some small precipitates.
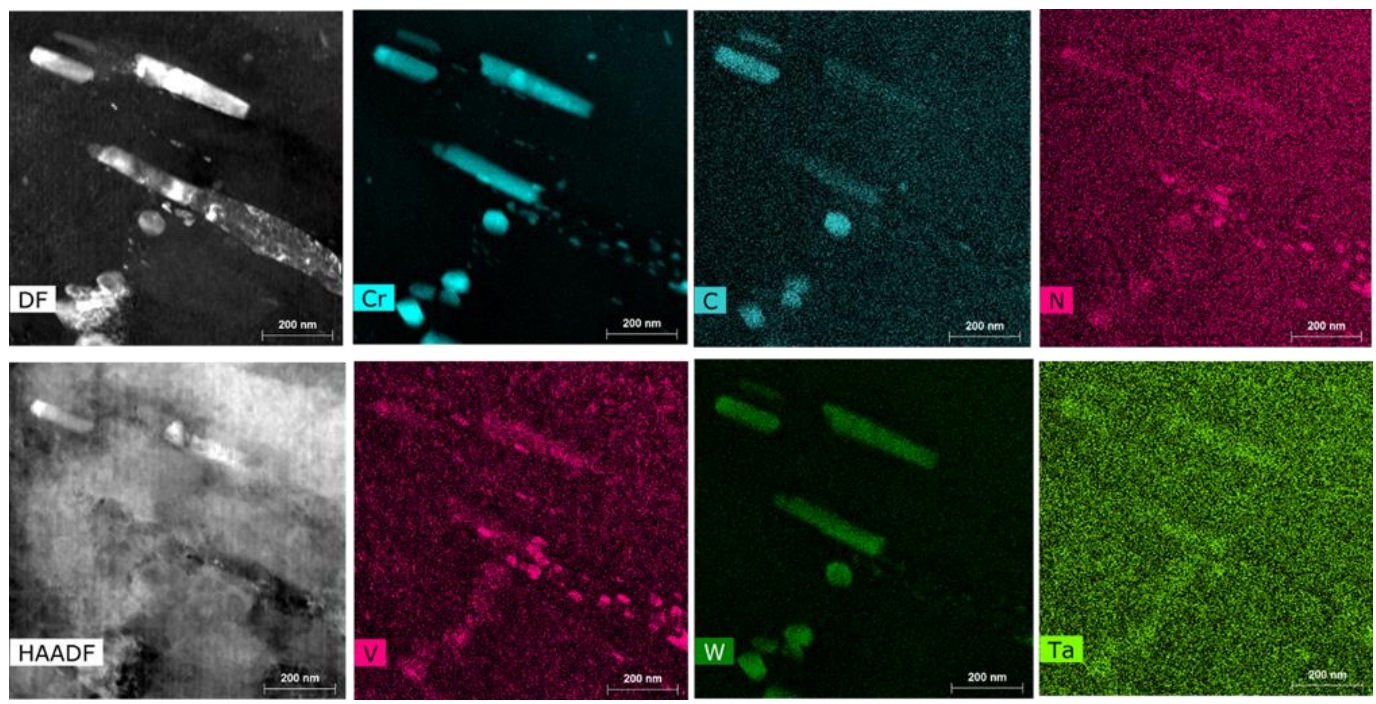

Figure 25: STEM-EDX mapping of precipitates in L series steel, along with an MAADF (DF) and HAADF. 
After irradiation, Figure 26 presents an overview of the lath structure and STEM-EDX maps. The lath structure appeared stable after irradiation, with no drastic differences as compared to nonirradiated results reported in Refs. [1,3]. The precipitate microstructure also looked similar to the one recorded before irradiation with large $\mathrm{Cr}$, W rich carbides located primarily on the lath boundaries, while $\mathrm{Cr}$, $\mathrm{V}$ rich smaller particles located inside the grains (but also on the lath boundaries). Only a few Ta rich precipitates were detected, which further confirmed a lack of MX phase in this alloy. To clearly distinguish the large $\mathrm{Cr}$ rich carbides $\left(\mathrm{M}_{23} \mathrm{C}_{6}\right.$ or $\left.\mathrm{M}_{7} \mathrm{C}_{3}\right)$ versus the $\mathrm{Cr}$, $\mathrm{V}$ rich precipitates $\left(\mathrm{M}_{2} \mathrm{X}\right.$ or $\left.\mathrm{MX}\right)$, the count maps of $\mathrm{Cr}$ and $\mathrm{V}$ are overlayed in Figure 27.
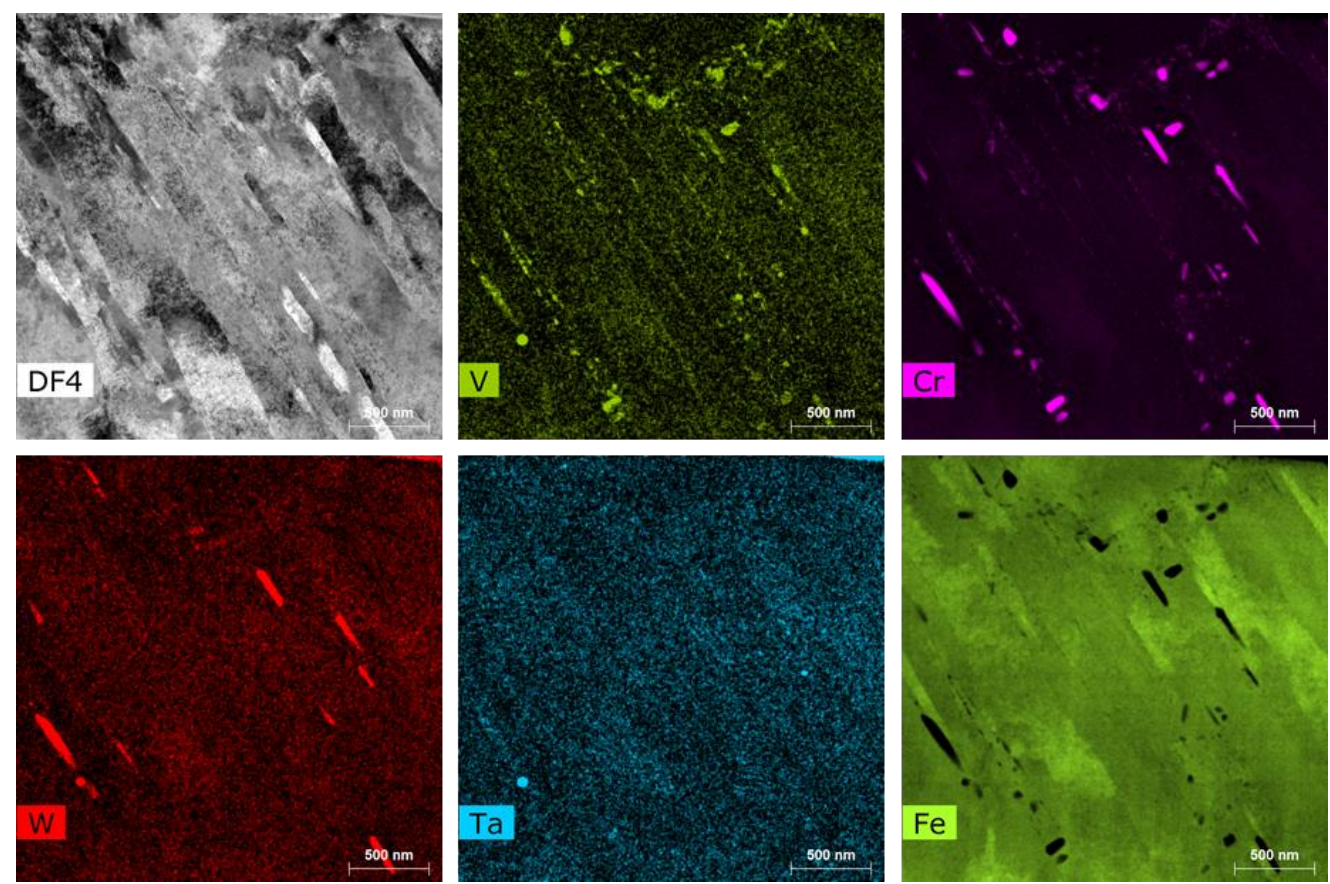

Figure 26: Characterization of $\mathrm{L}$ series steel after irradiation. LAADF image of the laths is presented along with STEM-EDX maps of the same area showing the precipitate distribution.

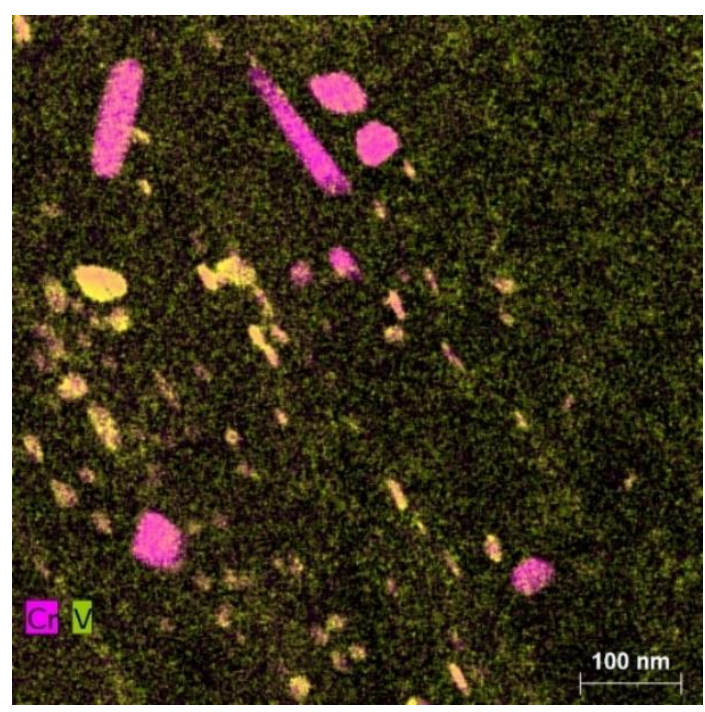

Figure 27: Overlay of Cr and V STEM-EDX maps to show the different precipitate families in L series steel after neutron irradiation. 
Dislocation loops formed in material $\mathrm{L}$ after irradiation. This can be seen in the different BF STEM images shown in Figure 28. While a g.b analysis was not possible due to the difficulty of tilting very fine nanometric laths to different orientations, some indication of the Burgers vector was obtained from the laths close to [001] orientation. In Figure 28b and c, numerous dislocation loops appeared close to on-edge condition with elongated coffee bean contrast when imaged with $\langle 110\rangle$ type diffraction vectors available along a [001] zone axis. Only a<100> type loops appear on-edge under such imaging conditions in bcc metals, which shows that the on-edge loops in Figure 28 were mostly a $<100\rangle$ loops. These results are consistent with results on material $\mathrm{J}$ in the previous section, and supports the hypothesis that under neutron irradiation conditions, a $<100>$ loops can form in large quantities at temperatures as low as $300{ }^{\circ} \mathrm{C}$ and this behavior is different from decades of data produced by ion irradiations in the $\mathrm{Fe}-\mathrm{Cr}$ system. The loops in material $\mathrm{L}$ were large, ranging between $\sim 10-45 \mathrm{~nm}$ in diameter.
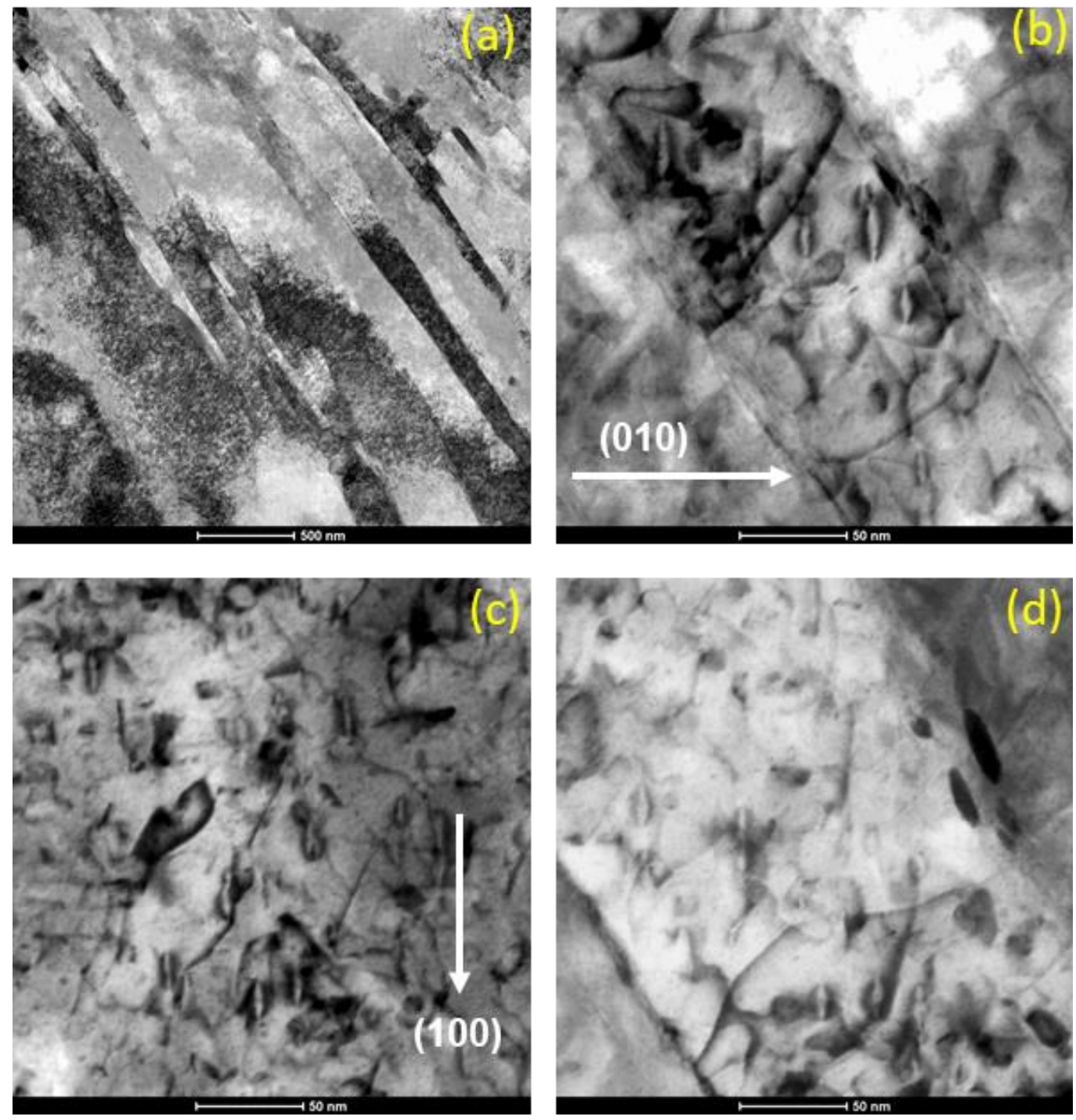

Figure 28: Characterization of dislocation loops in neutron irradiated L series steel using STEM-BF imaging. (a) Overview of the lath structures with dislocation loops. (a) Dislocation loops inside a nanometric lath; loops aligned close to on-edge condition when imaged close to [001] zone axis with a $<110>$ type g vector. (b, c) Similar loops detected in different laths that were also imaged close to [001] zone axis. 


\subsubsection{M series steels: ENEA}

Material $\mathrm{M}$ was the double austenized version of Eurofer97. In nonirradiated condition, TEM/STEM imaging of M series steel are presented in Figure 29. Due to high Ta content, round MX carbides were easily recognizable in the HAADF images where they appeared bright on a relatively dark background. EDX maps obtained from the same zone on which STEM was performed are presented in Figure 30, where the bright objects in HAADF images were confirmed to be Ta rich phase (expected to be MX), while the larger precipitates (>100-150 nm) rich in $\mathrm{Cr}$, W are expected to $\mathrm{M}_{23} \mathrm{C}_{6}$

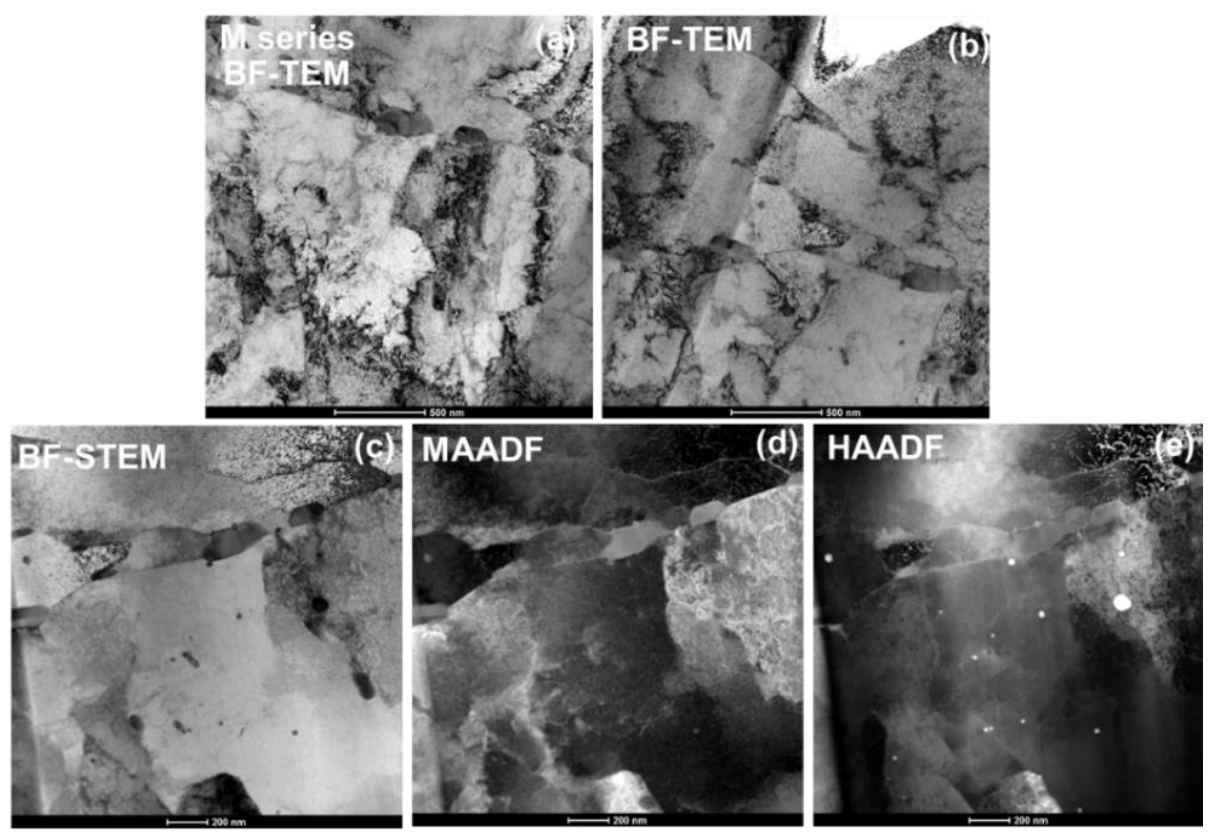

Figure 29: TEM/STEM imaging of nonirradiated $M$ series steel. (a, b) BF TEM images. (c, d, e) STEM BF, MAADF and HAADF images of the same zone showing precipitates. (f, g, h) STEM BF, MAADF and HAADF images.
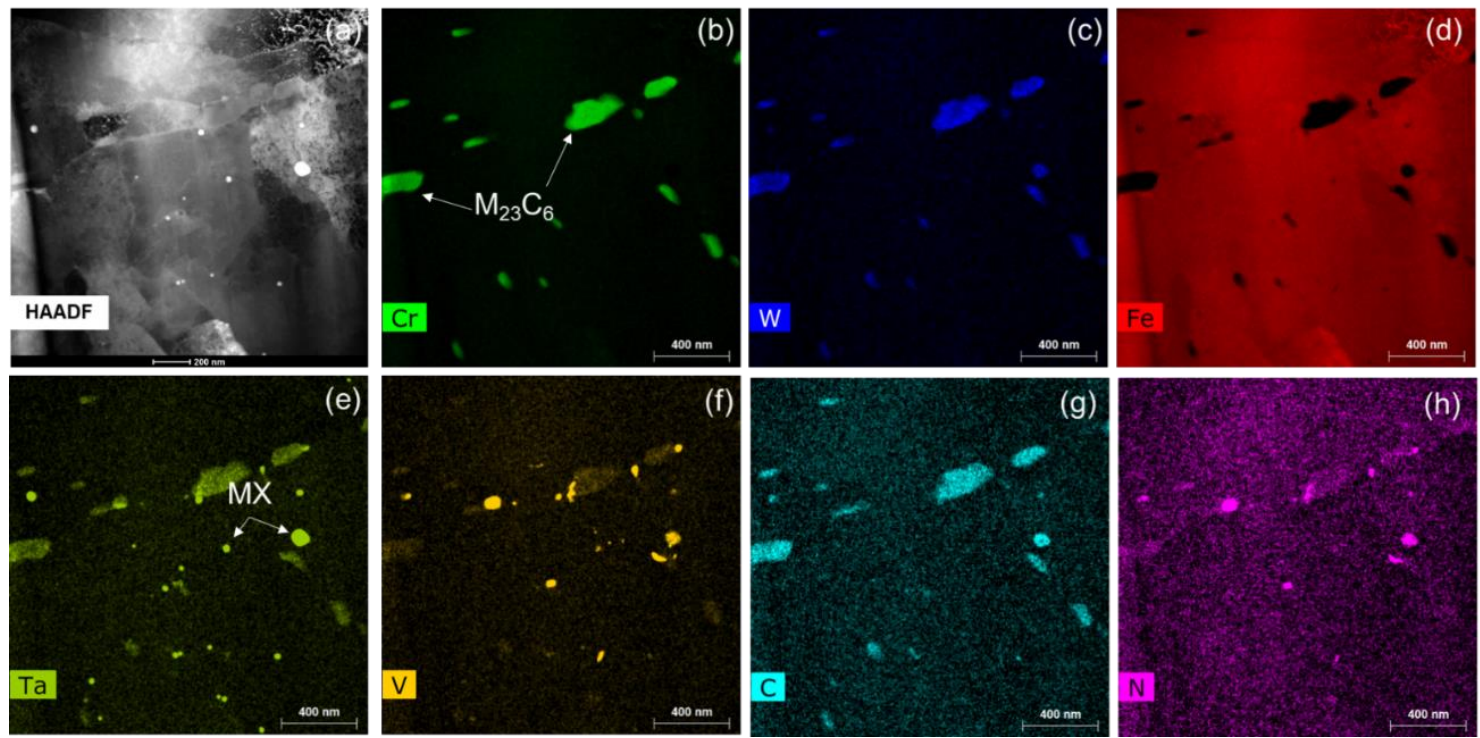

Figure 30: TEM and STEM imaging of $M$ series steel. (a, b) BF TEM images. (c, d, e) STEM BF, MAADF and HAADF images of the same zone showing precipitates. (f, $g, h$ ) STEM BF, MAADF and HAADF images in a different FIB foil of same zone. 
After irradiation, EDX mapping on material $\mathrm{M}$ was not performed because data from the previous alloys suggested no major degradation of the particles after the irradiations (except for the peculiar observations in material E). The microstructure of this steel after irradiation consisted of dislocation loops. The loop diameters ranged between as low as $\sim 3-4 \mathrm{~nm}$ to as high as $51 \mathrm{~nm}$. In Figure 31, an overview of the dislocation loop microstructure in this steel is presented. Similar to material $\mathrm{L}$ and $\mathrm{J}$, there appears to be presence of a $<100>$ type loops, indicated by the red arrows in the figure. Such loops were close to on-edge configuration when imaged with g vectors available in a [001] zone axis and were aligned along the general $<100>$ directions. However, comparing Figure 31 with imaging from material L and $\mathrm{J}$ suggests the fraction of such a $<100>$ loops are lower in material M. In Figure 31, all the dislocation loops that do not appear close to on-edge (coffee bean like contrast) are expected to be the $a / 2<111>$ type. Higher magnification images showing loops in this material are presented in Figure 32.
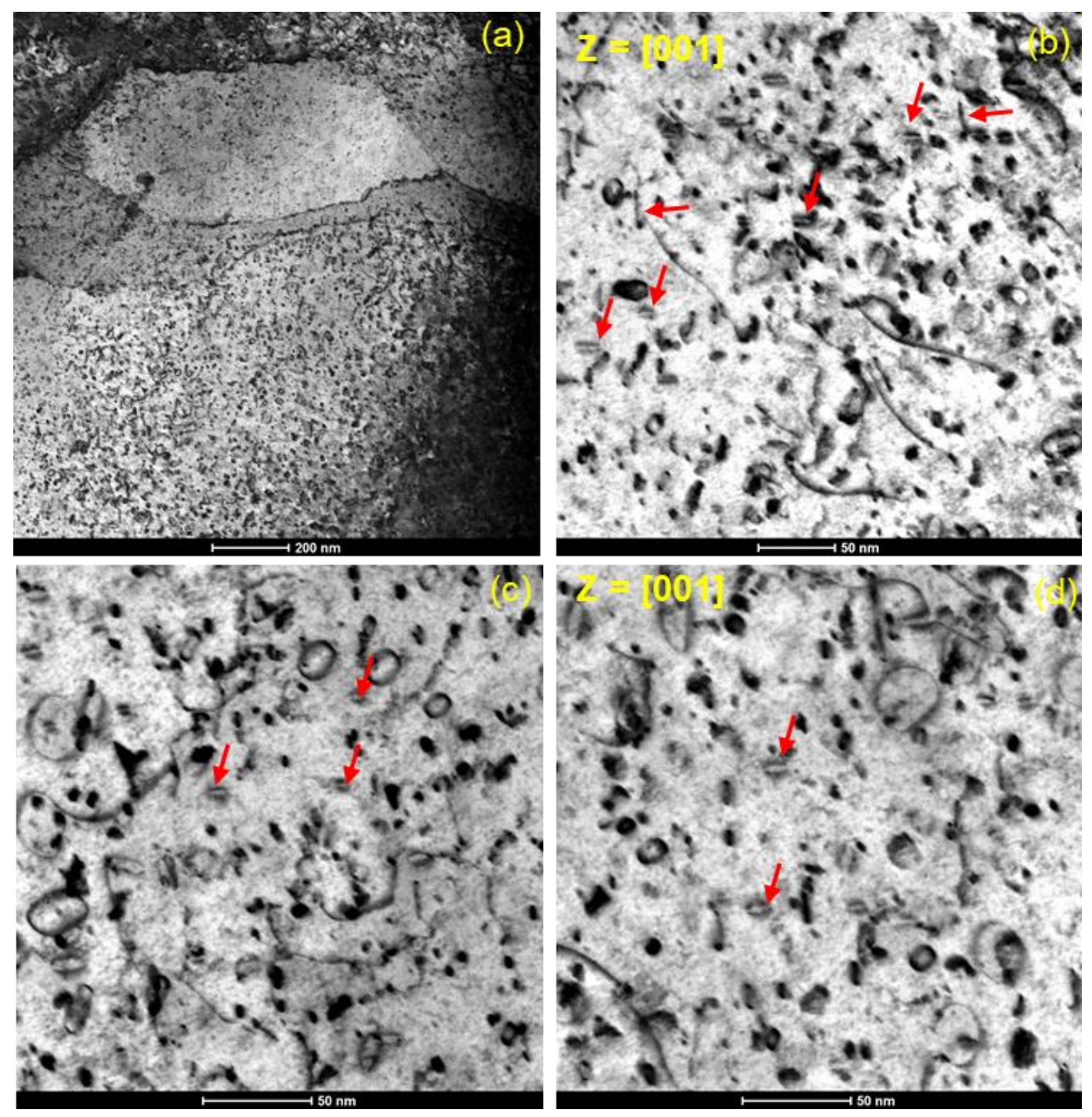

Figure 31: STEM BF imaging of dislocation loops in material $M$ after neutron irradiation. (a) Overview of the grains and the defect structures. (b, c, d) Dislocation loops imaged close to [001] zone axis with a $<110>$ type $g$ vector. Loops appearing close to on-edge as elongated coffee-beans (expected to be a<100> type) are indicated using red arrows. 

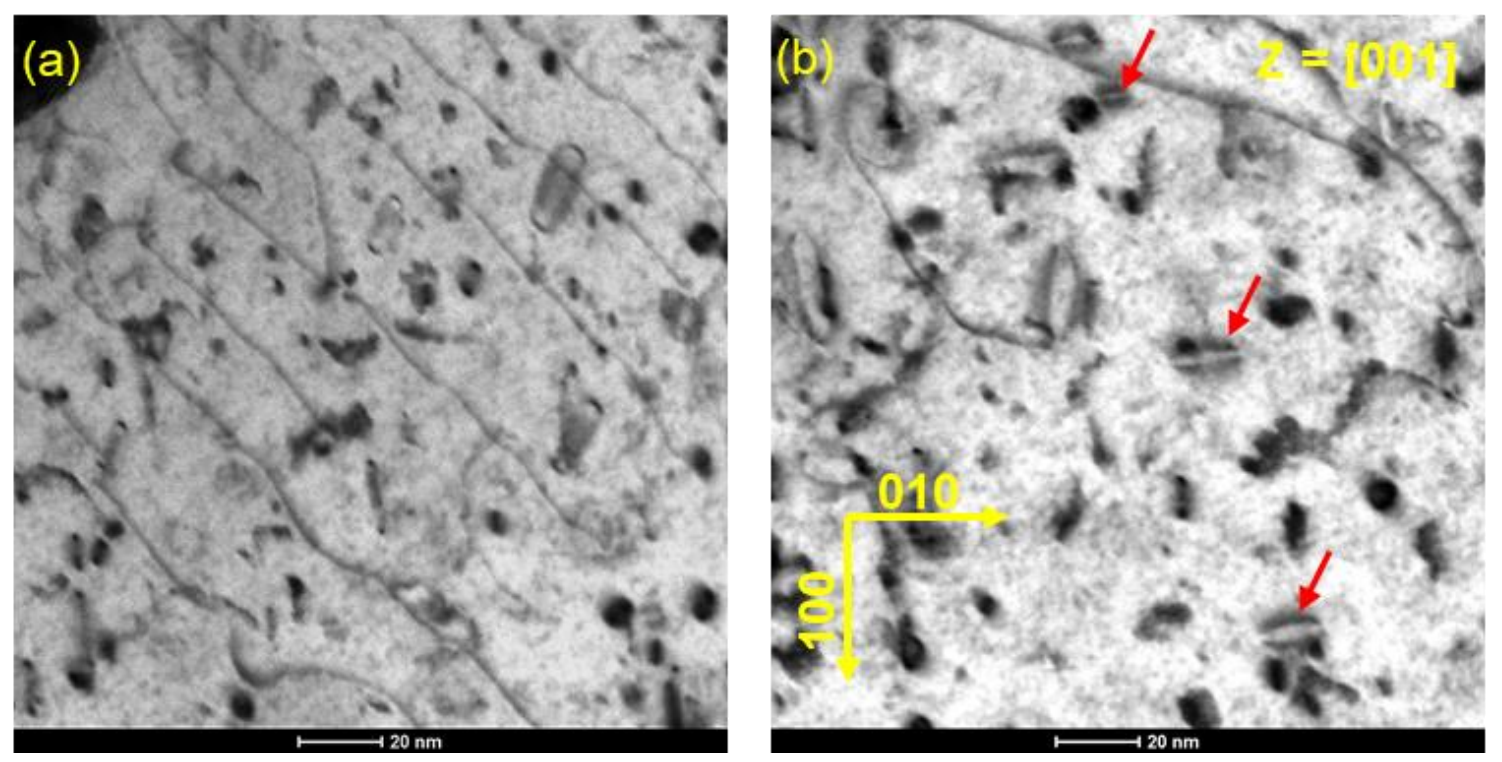

Figure 32: STEM BF imaging of dislocation loops in material $M$ after neutron irradiation. (a, b) High magnification micrographs of dislocation loops imaged close to [001] zone axis with a $\langle 110\rangle$ type $g$ vector. Red arrows indicate loops close to on-edge configuration aligned along $\langle 100\rangle$ directions, indicating they are a $<100>$ type.

\subsubsection{N series steels: ENEA}

Material $\mathrm{N}$ was similar to $\mathrm{M}$ as it was also double austenized, however it consisted of different chemistry. In nonirradiated condition, the starting precipitate distribution of $\mathrm{N}$ was similar to $\mathrm{M}$ (as highlighted in Ref. [1]). There were large globular MX particles, visible in the STEM images in Figure 33 and Figure 34.

After irradiation, similar to the results in other alloys, the precipitate microstructure did not alter much. The microstructure still showed the presence of large $\mathrm{Cr}$ rich carbides that are expected to be $\mathrm{M}_{23} \mathrm{C}_{6}$ and Ta rich MX carbonitrides. Because of a lack of vanadium in the alloy, the MX carbide appear as vanadium free in the STEM-EDX maps (Figure 35).

Dislocation loops formed in this material upon irradiation. A large overview of the loop microstructure is presented in the LAADF image in Figure 36. The diameters of the dislocation loops in this material were similar to material M, ranging between $\sim 3 \mathrm{~nm}$ to $57 \mathrm{~nm}$, and a number density of $1.04 \times 10^{20} \mathrm{~m}^{-3}$. A relatively high magnification overview using STEM BF imaging is presented in Figure 37. While the imaging was performed close to [001] zone axis, except a few features, there was no obvious presence of on-edge loops. This suggests a lack of a $<100>$ loops in this material. This difference in the loop population versus the other alloys needs careful future fundamental investigation. Chemistry of an alloy affects the nature and type of dislocation loops in the $\mathrm{FeCr}$ system. It is quite likely that subtle changes in the chemistries of the different alloys has an effect on the relative population of a $<100>v s \mathrm{a} / 2<111>$ type loop types. 

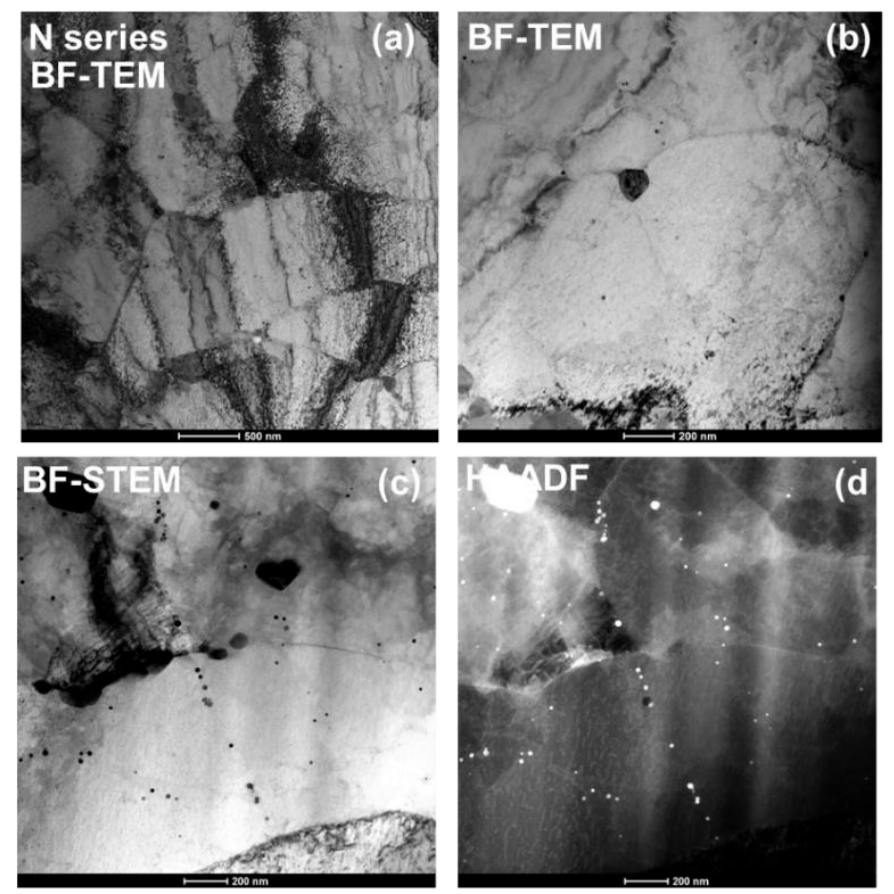

Figure 33: TEM/STEM imaging of the nonirradiated microstutruees of material $N(a, b)$ BF TEM images showing the general microstructures. (c, d) BF STEM and HAADF image of the same zone showing MX carbonitrides in the steel.
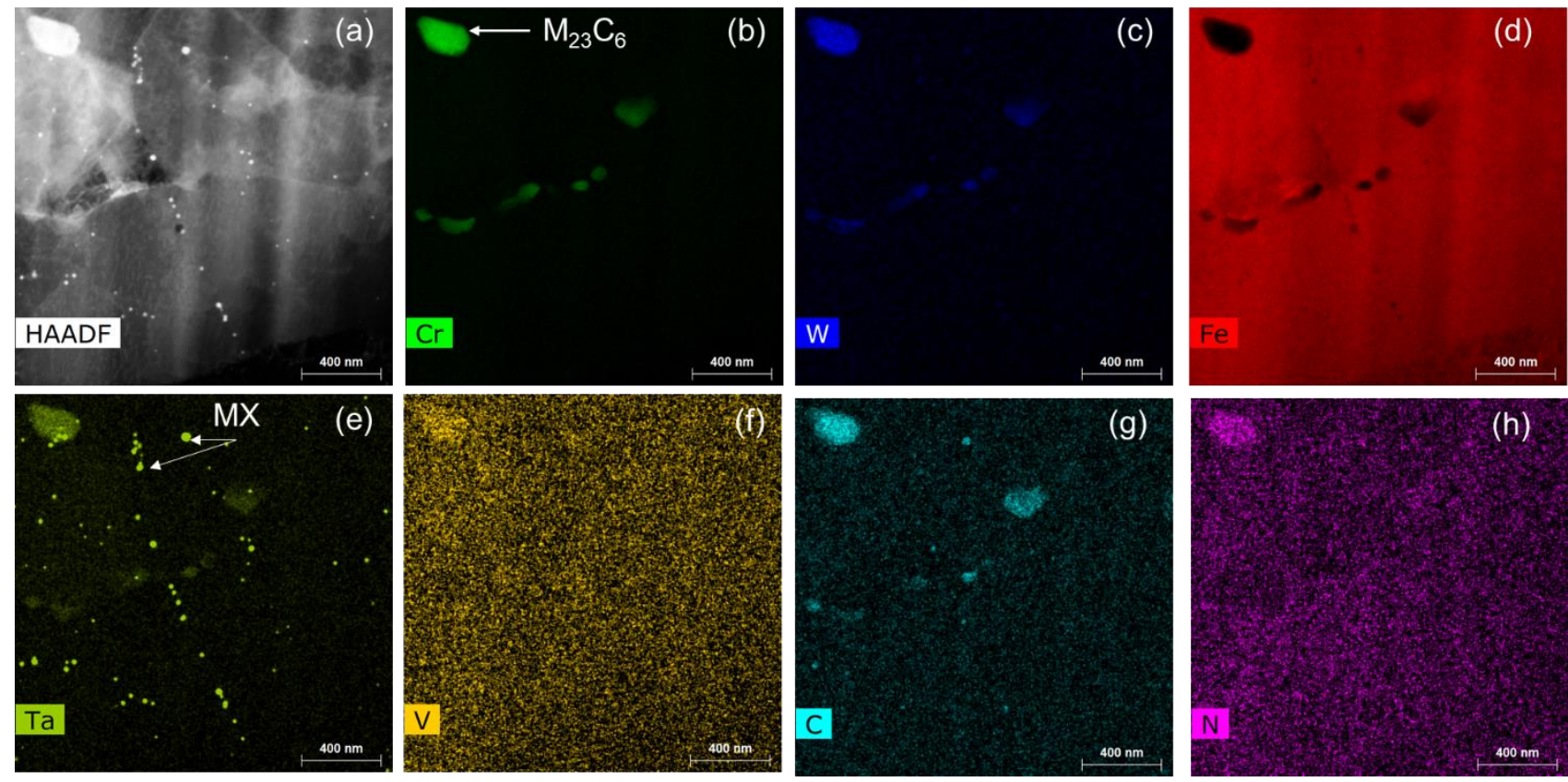

Figure 34: Analytical STEM characterization of the nonirradiated material N microstructure. (a) HAADF image of a zone which is the same zone as in Fig, 33. (b-h) STEM-EDX mapping showing elemental distribution. 

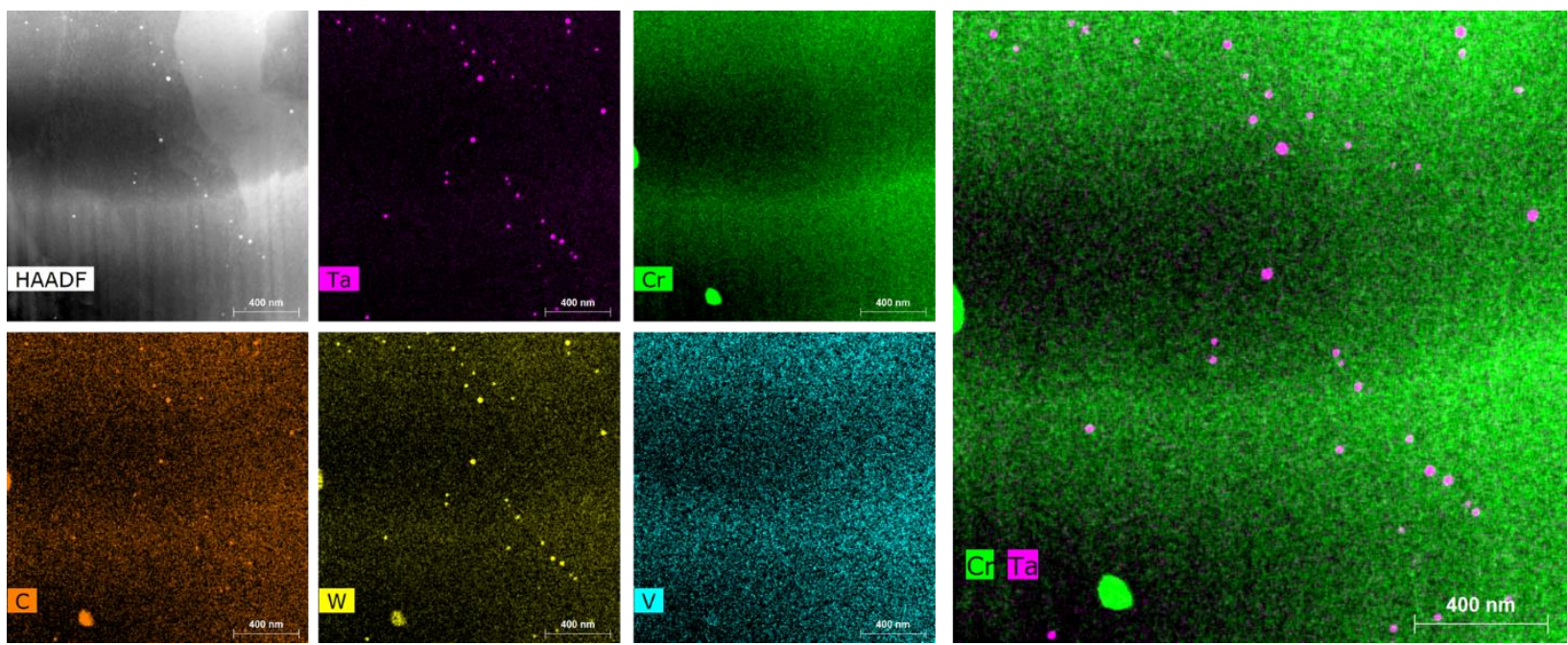

Figure 35: Analytical STEM characterization of the HFIR irradiated material N. An overlay of $\mathrm{Cr}$ and Ta map is also presented to identify the distribution of MX in this alloy.

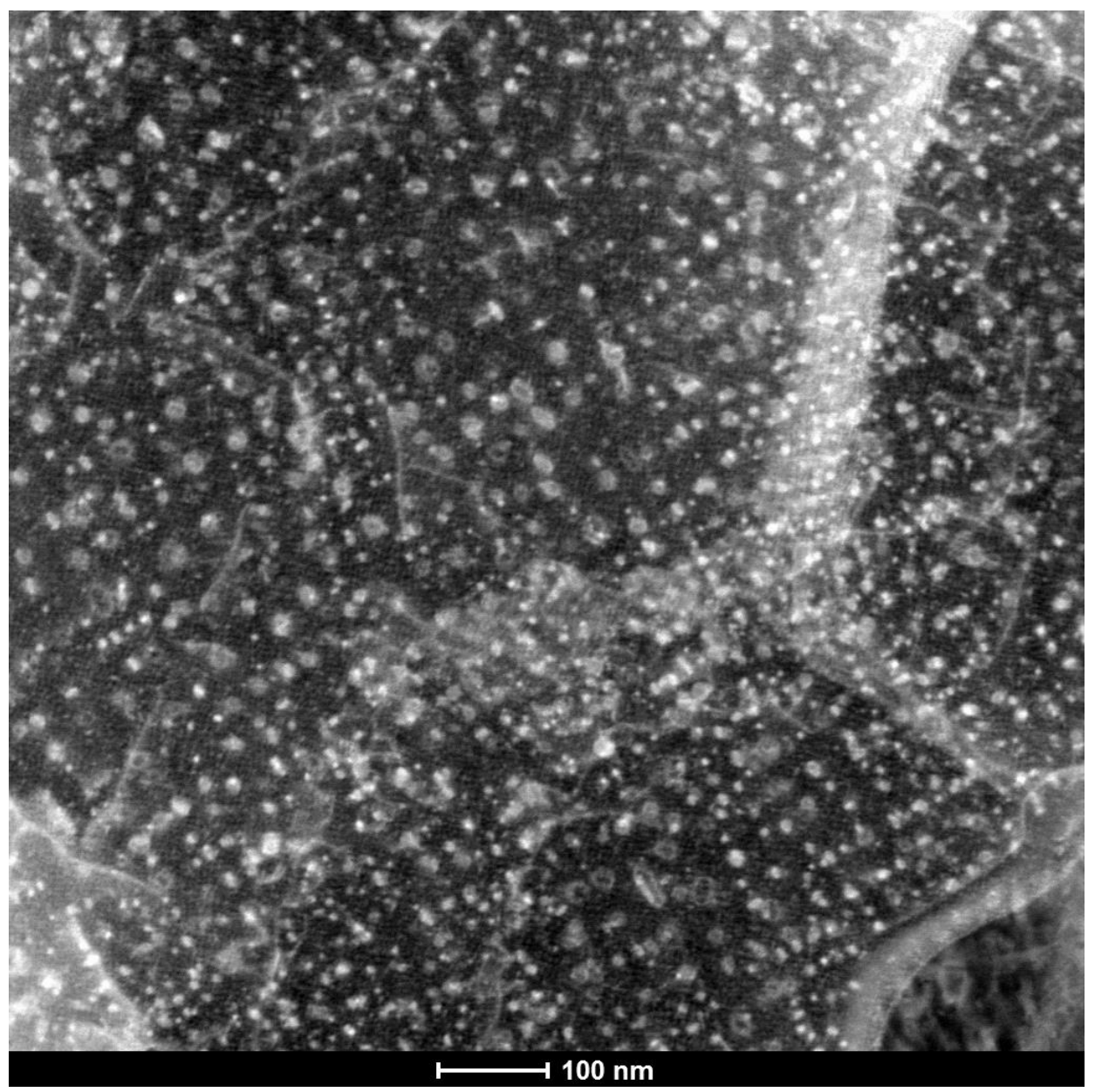

Figure 36: LAADF STEM image showing the dislocation loop distribution in the material $\mathrm{N}$ after HFIR irradiations. 


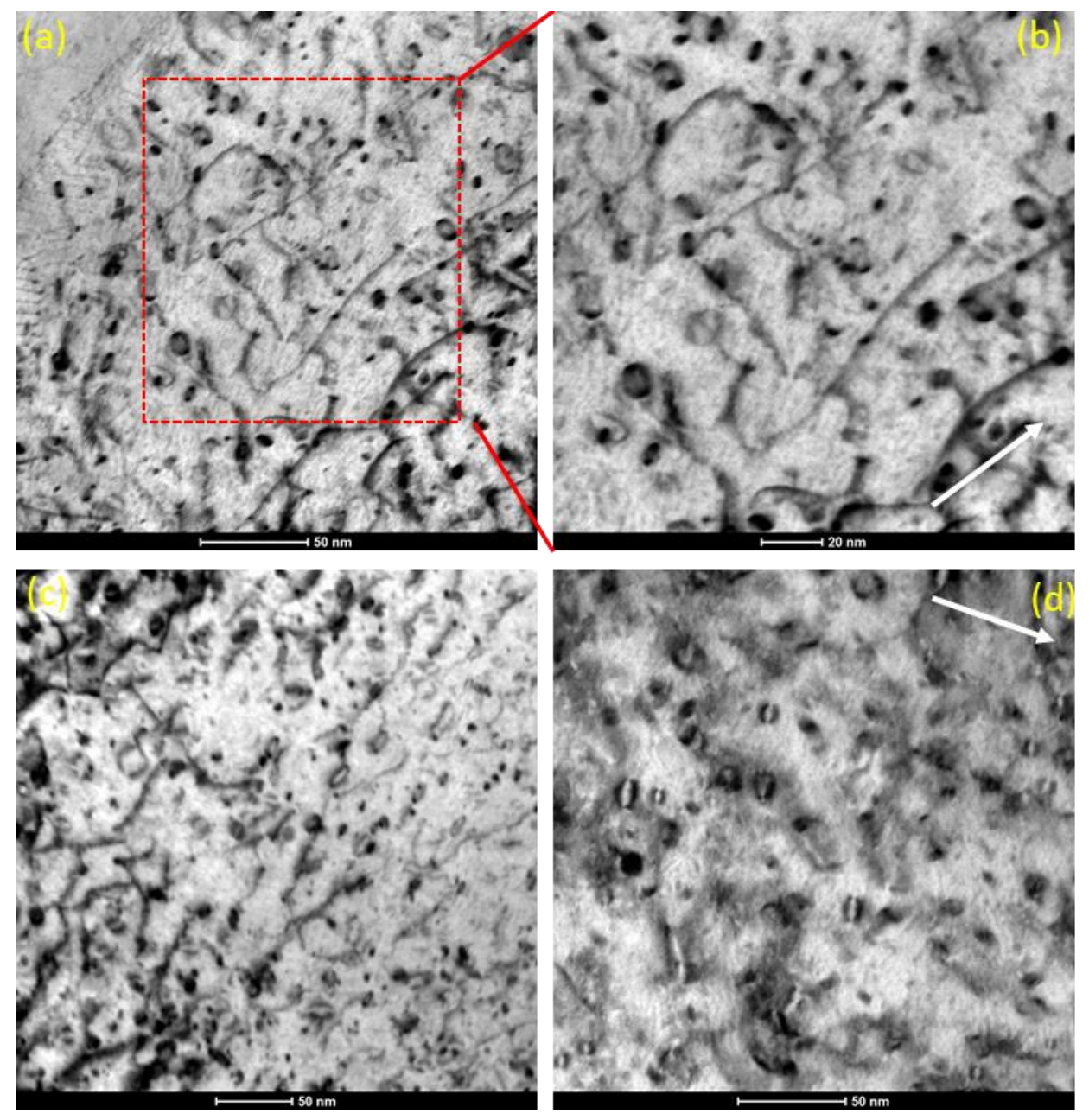

Figure 37: BF STEM images of dislocation loops in material N. (a) Overview of a region showing an area of analysis. (b) High magnification image of the square area in (a). (c and d) Two different locations in the foil that were imaged close to [001] zone axis.

\subsubsection{O series steels: ENEA}

Material $\mathrm{O}$ was the alloy containing textured grains due to deformation given at low temperatures. In nonirradiated conditions at TEM length scale, its microstructure was similar to the other alloys with presence of $\mathrm{M}_{23} \mathrm{C}_{6}$ carbides and $\mathrm{V}$ rich features expected to be MX. Because most other steels did not show a dramatic change to their precipitate microstructure after irradiation, any changes to the precipitates in material $\mathrm{O}$ is also not expected. After irradiation, the microstructure of material $\mathrm{O}$ consisted of dislocation loops. However, the loop microstructure appeared more dense that in other alloys, presumably because of a higher starting dislocation density as a result of which the dislocation loops and dislocation lines showed heavy interaction. Figure 39 shows a STEM BF and LAADF image of the irradiated material $\mathrm{O}$ where the complexity of the irradiated microstructure can be seen. Numerous identified dislocation loops are indicated by red arrows in the figure. The loop size ranged between $4 \mathrm{~nm}$ to as high as $52 \mathrm{~nm}$, which is a similar observation to the previous few alloys. The dislocation loop number density was $3.3 \times 10^{20} / \mathrm{m}^{-3}$. 

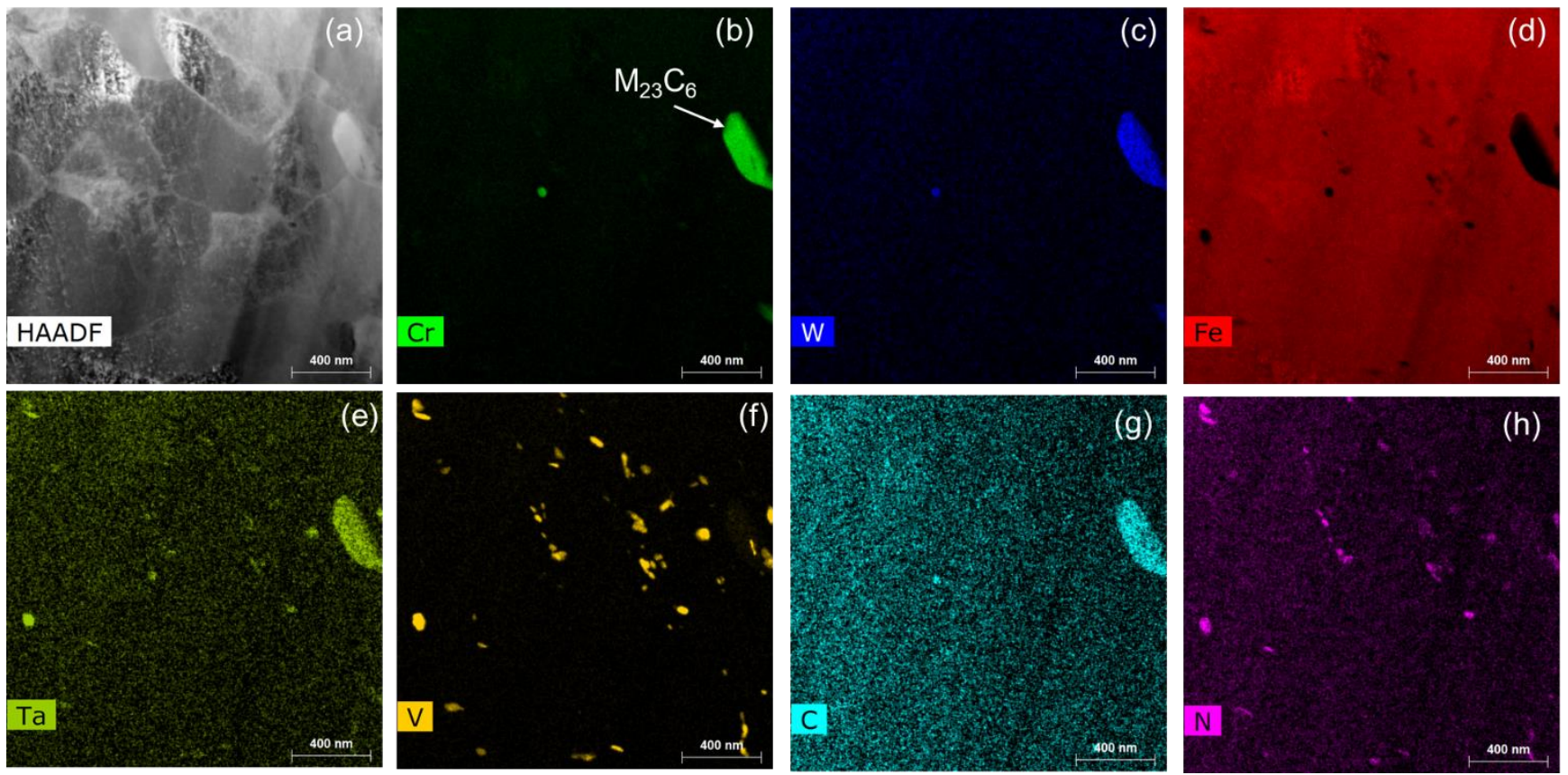

Figure 38: STEM-EDX mapping of nonirradiated O series steel (a) HAADF image (b-h) EDX maps of same zone.
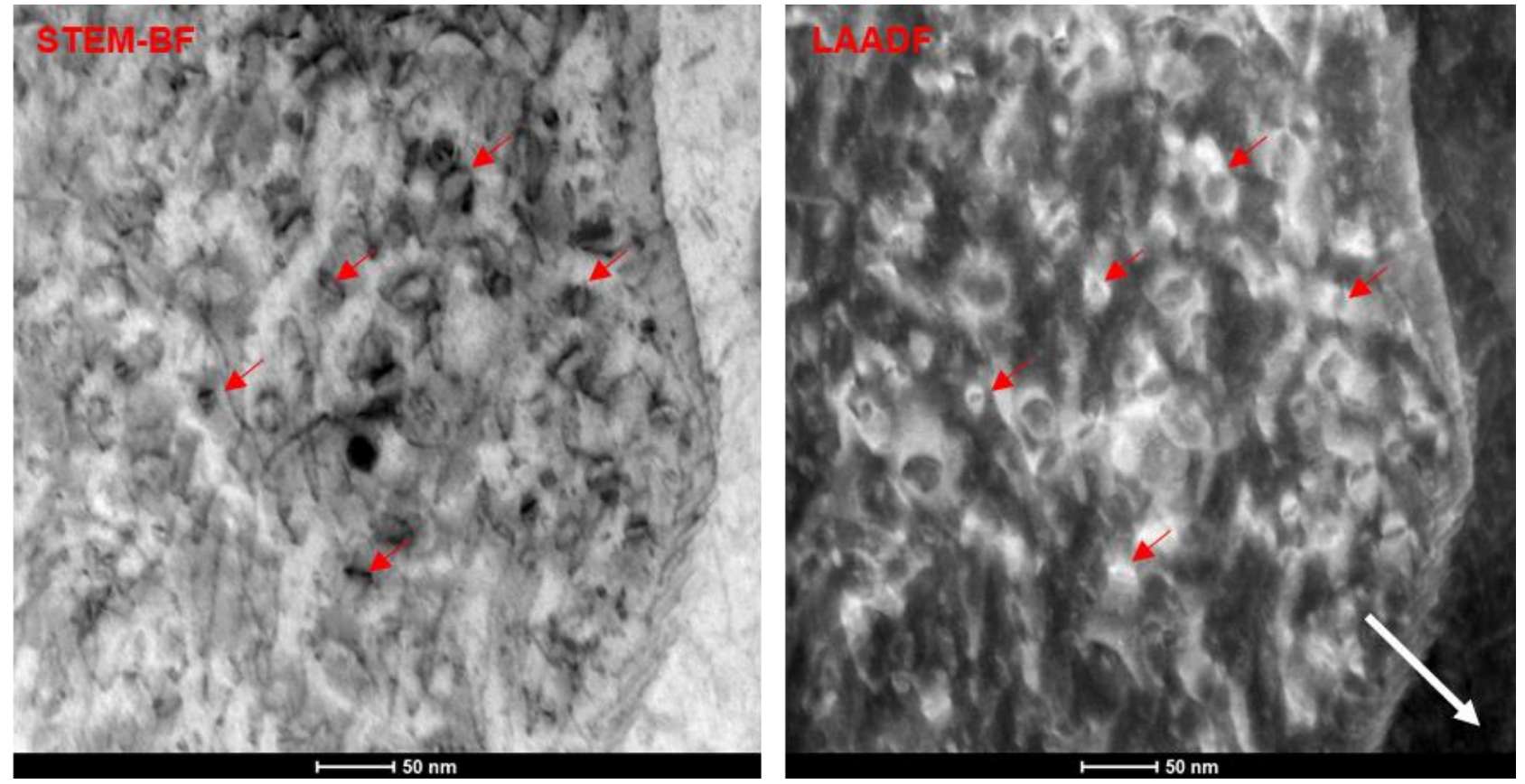

Figure 39: STEM-BF and LAADF imaging of the same zone in irradiated material $\mathrm{O}$ showing dislocation loops. Some identified loops are indicated using red arrows. Zone axis $=[101], g=(-101)$. The direction of the $g$ vector is annotated in the figure with a white arrow. 


\subsubsection{E series steels: KIT}

Material E was Eurofer97 which was given a technological treatment to simulate abnormal conditions occurring during the fabrication process or during welding. In the nonirradiated condition, this alloy consisted of very coarse carbides (reported in Refs. [1,2]). However, such coarse carbides were not detectable in FIB foils because of smaller area of analysis. From Ref. [1], the overview of the initial microstructures characterized using STEM is presented in Figure 40. After irradiation, data from most previous steels has shown negligible changes to the precipitate microstructure of the alloys. So, STEMEDX on this alloy was not performed. However, the irradiated microstructures showed a large network of entangled dislocation loops. This can be seen in the LAADF image in Figure 41. A series of STEM-BF and HAADF imaging of the same areas of an irradiated foil is presented in Figure 42 where the entangled network of loops/dislocations can be seen. For this reason, g.b analysis or estimating size or number density of dislocation loops was not possible for this sample. In Figure 42, the associated HAADF images show the coarse MX carbides in the alloy.
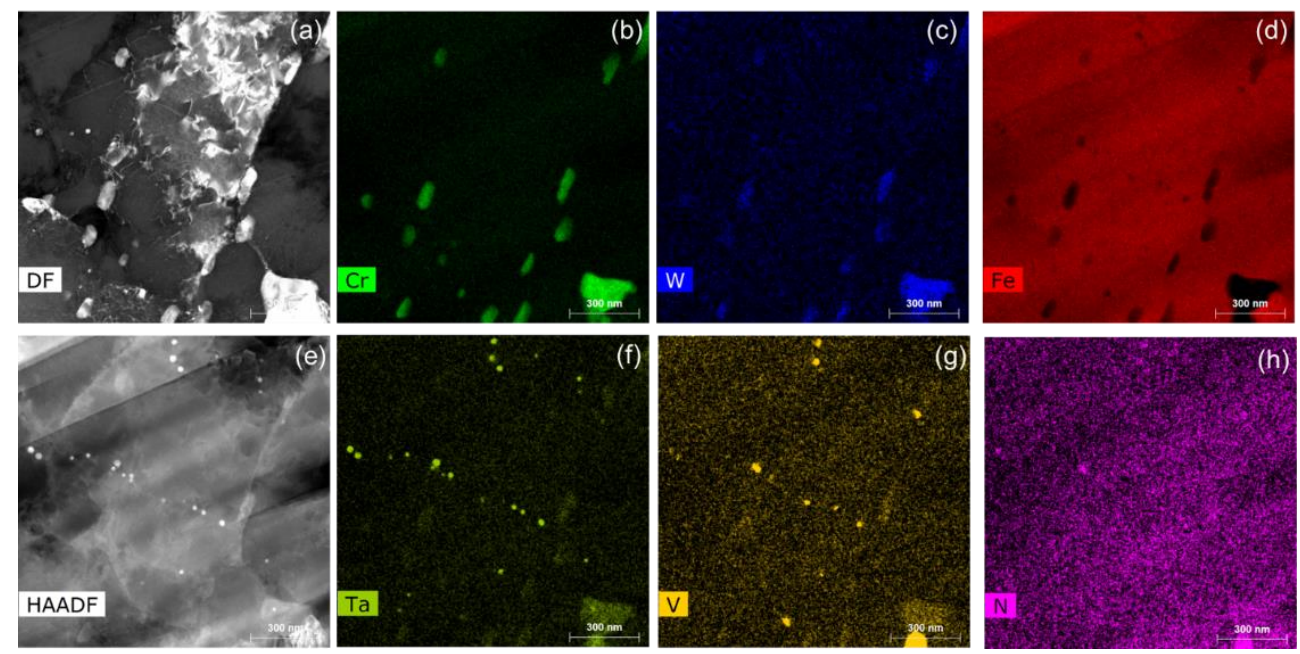

Figure 40 STEM imaging and EDX mapping of E series steel in nonirradiated condition.

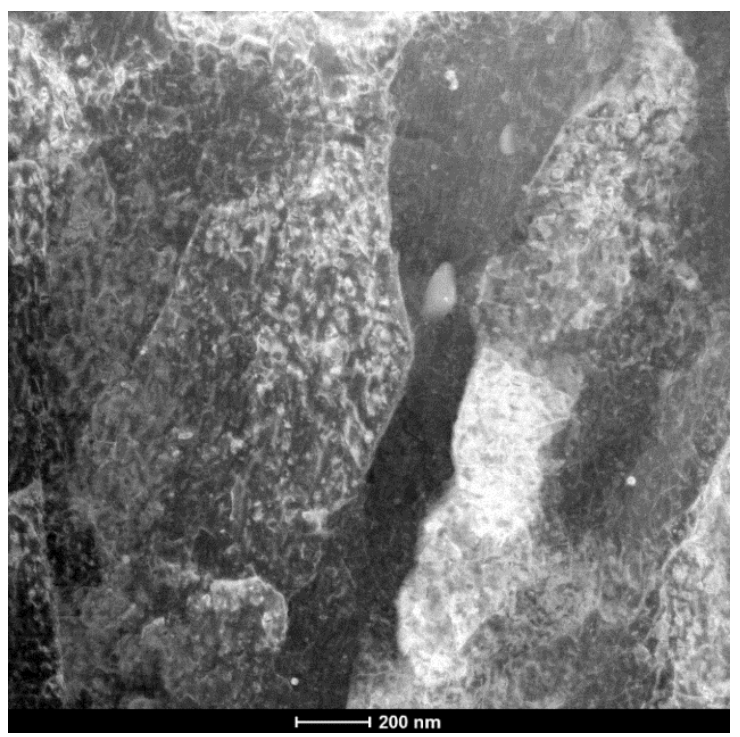

Figure 41: LAADF STEM image overview of irradiated material N. The bright features shows an entangled network of dislocation loops. 

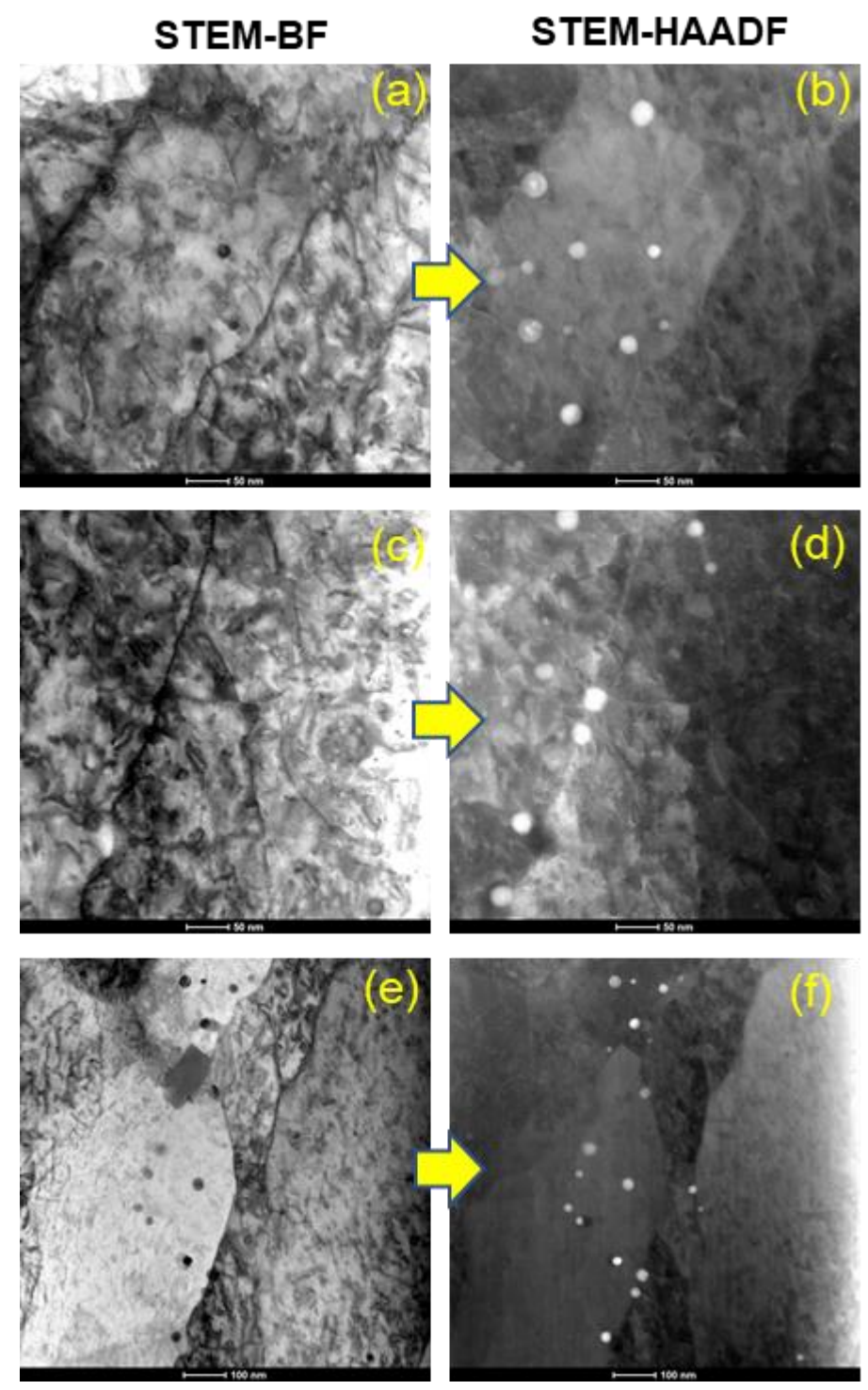

Figure 42: Series of BF STEM and HAADF images showing the irradiated microstructures of material E. The loops formed a dense entangled network in this material. Bright objects in the HAADF images are the coarse MX type carbonitrides. The HAADF images are recorded form the same area where BF imaging was performed.

\section{References}

[1] A. Bhattacharya. X. Chen, K. Linton, Y. Yamamoto, M. Sokolov, L. Clowers, Y. Katoh, Mechanical properties and microstructure characterization of unirradiated Eurofer-97 steel variants for the EUROfusion project, ORNL/SPR-2018/882, 2018, doi:10.2172/1471901.

[2] A. Bhattacharya, X. Chen, T. Graening, J. Reed, J.W. Geringer, Y. Katoh Post-irradiation examination of Eurofer97 steel variants irradiated to $2.5 \mathrm{dpa}, \sim 300{ }^{\circ} \mathrm{C}$ in HFIR for the EUROfusion program, ORNL/SPR-2020/1440 (2020).

[3] A. Bhattacharya, C.M. Parish, J. Henry, Y. Katoh, High throughput crystal structure and composition mapping of crystalline nanoprecipitates in alloys by transmission Kikuchi diffraction and analytical electron microscopy, Ultramicroscopy, 202 (2019) 33-43, https://doi.org/10.1016/j.ultramic.2019.03.015 